\title{
Recent development of plasmon-mediated photocatalysts and their potential in selective/activity enhancement and selectivity regulation
}

\author{
Xingguang Zhang*a, Xuebin Ke*b, Jianfeng Yao*a
}

\begin{abstract}
Address a: College of Chemical Engineering, Nanjing Forestry University, No. 159, Longpan Road, Nanjing, 210037, Jiangsu, P.R. China

Address b: School of Chemical Engineering, University of Hull, United Kingdom

Emails: x.g.zhang@njfu.edu.cn, x.ke@hull.ac.uk, jianfengyao@163.com
\end{abstract}

\begin{abstract}
It has long been attracting people's attention to explore solar energy as drive for conventional chemical production with high product selectivity under ambient conditions. To this end, the development of photocatalytic nanomaterials as antennas to absorb light irradiation plays a pivotal role. Hence, catalysis science and technology plays an indispensable role in these transformations in order to achieve a high conversion and selectivity. This review mainly deals with the development of photocatalytic plasmonic nanomaterials in clean chemicals synthesis and highlights the mechanism on regulating catalytic selectivity.
\end{abstract}

\section{Introduction}

Photocatalysis plays a pivotal role in solar energy harvesting, clean chemicals synthesis, materials development and environmental technology, 1, 2, 3, 4 owing to its advantages compared with conventional heatdriven catalysis which generally depends on high thermal energy and thus offers a low product selectivity. Traditional photocatalysis primarily focuses on $\mathrm{TiO}_{2}-$ based photocatalysts that absorb limited UV light (4\% of sunlight). ${ }^{5}, \quad 6,7$ In this regard, visible-light driven photocatalysts are in request; recent years have seen the development of plasmonic photocatalysts on the basis of $\mathrm{Au}, \mathrm{Ag}$, and $\mathrm{Cu}$ and thereafter newly-developed plasmonic photocatalysts such as $\mathrm{Pt}, \mathrm{Pd}, \mathrm{Al}$ and their alloys. ${ }^{8,9,10,11,12}$ Moreover, some non-metal plasmonic photocatalysts (e.g. molybdenum oxide nanosheets, ${ }^{13}$ $\mathrm{Cu}_{2-\mathrm{x}} \mathrm{S}$ nanodisks, ${ }^{14}$ and tungsten oxide nanocrystals ${ }^{15}$ have also been developed, which significantly enriches the scope of plasmonic nanomaterials and has made a pronounced progress.

The plasmonic effect of nanomaterials interacting with light can generally result in the generation of "hot electrons", ${ }^{16,} 17$ enhanced local electric fields, ${ }^{\mathbf{8}}$ charger separation (Shottky barrier on $\mathrm{TiO}_{2}$ ), ${ }^{18}$ photothermal effects (heating) and the like. ${ }^{19}$ In real catalytic reactions, researchers expect to utilise plasmon-mediated electrons generated on plasmonic nanostructures to offer strong interaction with reactants, and to maximise photo- chemical conversion efficiency, thus lowering activation energy to boost activity and creating new reaction pathway to manipulate product selectivity.

Despite plethora of reviews on plasmon-enhanced photocatalysis, ${ }^{20,} \mathbf{1 0}, 21$ this review paper principally concentrates on regulating catalytic selectivity of nanomaterials via their plasmonic effects and associated methods in chemical synthesis (excluding catalysts preparation technology, dyes degradation, drug delivery, biosynthesis, $\mathrm{CO}_{2}$ conversion, water splitting, and $\mathrm{H}_{2}$ production). Hence, such a review will provide an essential and much needed resource for guiding academic and industrial research. Such informed judgments are essential to selecting the most appropriate photocatalyitc materials for chemicals production and hopefully increasing the industry uptake of photocatalytic processes.

\section{Recently developed plasmonic nanomaterials}

\subsection{Au, Ag, Cu single metal-based photocatalysts}

Surface plasmons observed on metallic nanosctrucres was pioneered in the $1950 \mathrm{~s},{ }^{22}$ and $\mathrm{Au}, \mathrm{Ag}$, and $\mathrm{Cu}$ are most popular plamonic photocatalysts investigated by researchers for decades. ${ }^{23}$ To start, a brief introduction on the fundamental and principal theories of plasmonmediated phenomena are given, including Localised Surface Plasmon Resonance (LSPR), Electric Near-Field Enhancement (ENFE), and the Shotkey contact between 
plasmonics and semiconductors. These three representative features are intensively investigated in the plasmonic photocatalytic processes and are guiding principles to design composite photocatalysts.

\subsubsection{Localised surface plasmon resonance (LSPR)}

Surface plasmons are the collective oscillations of free electrons that are confined evanescently on a metal surface. ${ }^{24}$ Coupled with photons, surface plasmons can act as a collective excitation of conduction electrons that propagate in a wave-like manner along an interface between a metal and a dielectric, usually nanowire or nanofiber structures, known as surface plasmon polaritons, ${ }^{25}$ which are confined to the vicinity of the interface and can propagate along the metal surface until the energy dissipates, either by heat loss or by radiation into free space. Here we highlight the Localised Surface Plasmon Resonance effect that is oscillations of electron density confined on the plasmonic metal nanoparticles surface, ${ }^{8}$ as illustrate in Fig. 1. In detail, the electromagnetic field of incident light can cause the free electrons in gold nanoparticles (Au NPs) to oscillate. As the front wave of visible light passes, the electron density in the Au NPs are polarised to one side of the surfaces, and the free conduction electrons collectively and coherently oscillate in resonance with the light's frequency, causing a dynamic dipole oscillator, denoted as $\mathrm{Au}^{(\delta+-\delta)} \cdot{ }^{26}$ Moreover, the resonant localised surface plasmons, result in a large enhancement of the localised electromagnetic field and this will be discussed later on.
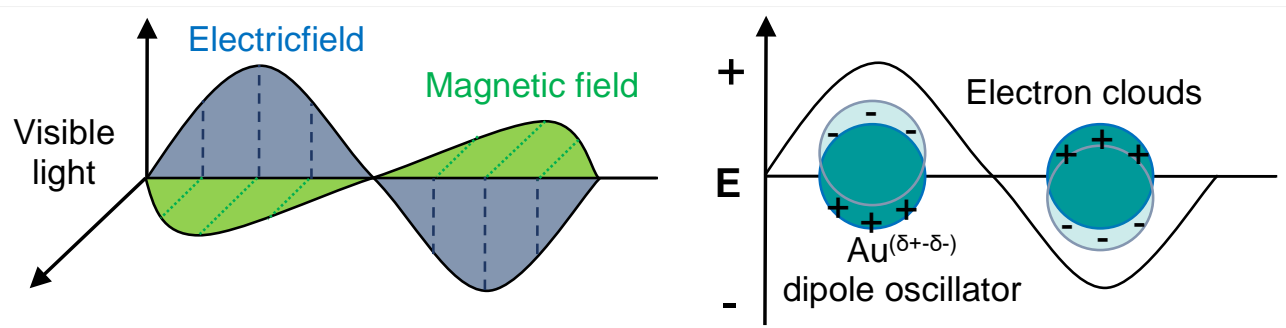

Fig. 1 The scheme of the electromagnetic field of visible light and its interaction with Au NPs: A dipole oscillator is induced, which resonates in phase with the electromagnetic field of the incoming visible light. Reproduced with permission from Ref. ${ }^{\mathbf{2 6}}$

Visible light usually undergoes intraband LSPR absorption (electrons in 6sp band), which is different from interband absorption when irradiated by ultraviolet light (electrons oscillate from $5 d$ to $6 s p$ ). ${ }^{27}$ This is still controversial, as illustrated in Fig. 2, some researchers propose that the absorption peak of Au nanostructures under visible light irradiation is contributed by both intraband and interband adsorption, and the apparent total absorption is their combination. ${ }^{28}$ These energetic electrons may return to their thermal equilibrium states and release heat to the lattice and the surrounding media, or can be grabbed by reactants to reduce them to initiate chemical reactions. ${ }^{19}$ Regarding the hot electrons, they may have two different pathways: (1) hot electrons transfer from the metal nanoparticle tunnels into the lowest unoccupied molecular orbital (LUMO) of the adsorbed molecule located nearby the metal nanoparticles, or (2) hot electrons transfer from the metal nanopartilces to the contacted supports (usually a semiconductor). ${ }^{29}$

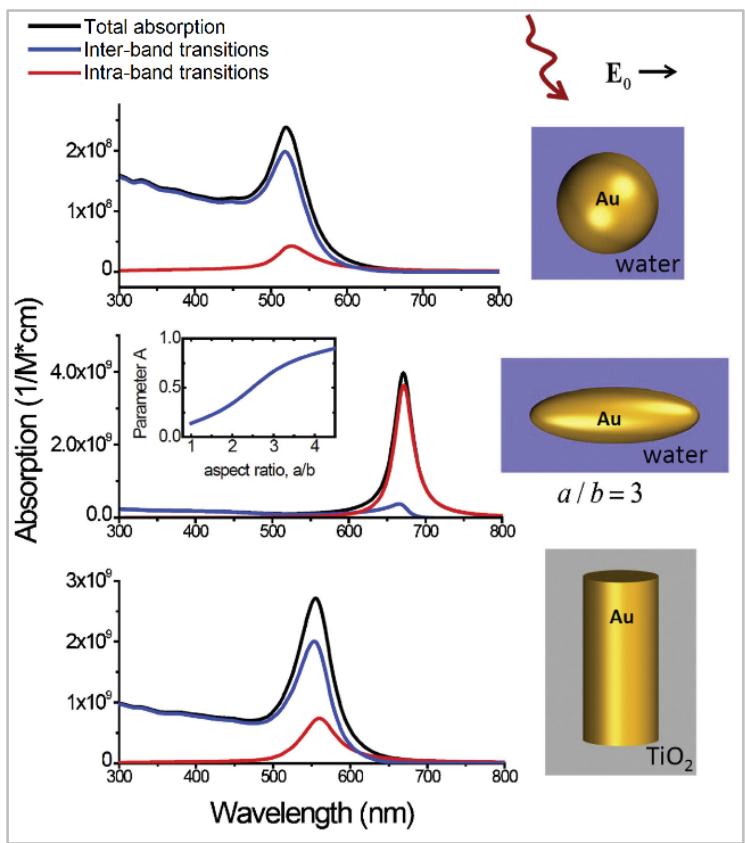

Fig. 2 The total absorption and contribution of the intraband and interband transitions. The insets show the dielectric models of the nanocrystals, on which the calculations were used. The inset in the middle graph shows the ratio of the intraband and total absorptions for a Au ellipsoid as a function of the parameter $a / b$, where $a$ and $b$ refer to the sizes of the ellipsoid. Reproduced with permission from Ref. ${ }^{28}$ 
The aforementioned theory regard the LSPR indicate that, if the size, shape, and surrounding materials of the metal nanoparticles change, then the electric field density of the surface of metal nanoparticles changes, thereby leading to a change in the oscillation frequency of electrons and in the LSPR peak positions. For instance, the free electrons in Au NPs can readily travel through the material, where the mean free path is about $50 \mathrm{~nm}$. If the size of Au NPs prepared is smaller than this dimension, then no scattering occurs from the gold bulk, and all interactions are on the gold surfaces. In general, if the size of Au NPs produced by chemical reduction of gold salts are smaller than half the wavelength of the incident light, then they can exhibit the LSPR effect. ${ }^{3}$ Moreover, $\mathrm{Au}, \mathrm{Ag}$, and Cu NPs and their alloys show different LSPR peak positions, as given in Fig. 3. All these properties afford a variety of adjustable photocatalytic performances of plasmonic nanostructures.
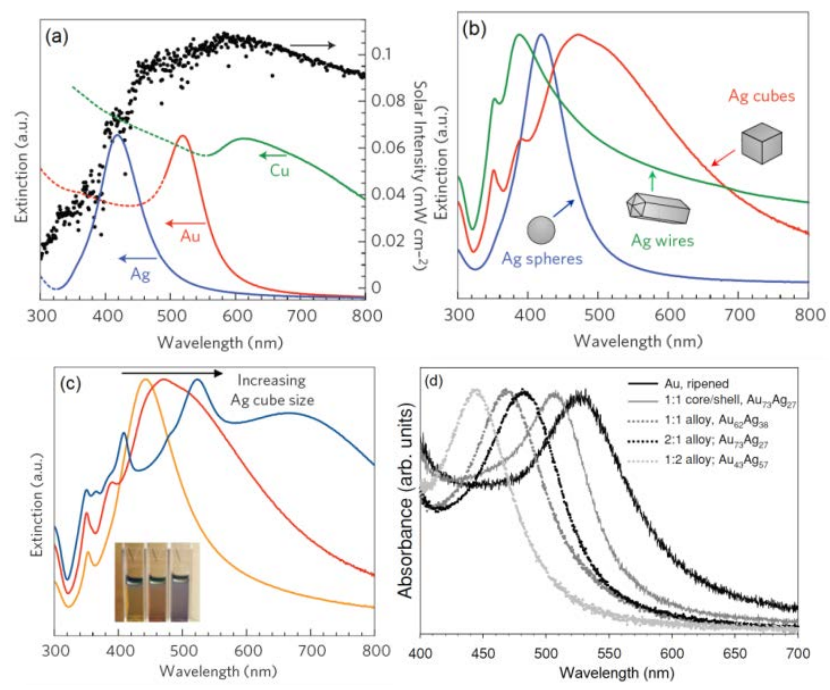

Fig. 3 LSPR bands of (a) $\mathrm{Au}, \mathrm{Ag}$, and $\mathrm{Cu}$ NPs; (b) $\mathrm{Ag}$ nanostructures with different shapes; (c) Ag nanocubes with different sizes; and (d) Au-Ag alloy with different compositions. Sets (a)-(c) are reproduced from Ref. ${ }^{8}$, and (d) is from Ref. ${ }^{30}$

\subsubsection{Electric near-field enhancement (ENFE)}

An important characteristic of the LSPR effect of plasmonic nanostructures is that it can amplify the electromagnetic field intensity of the incident light $\left(\left|\mathrm{E}_{0}\right|\right)$ and results in an enhanced electric field $(|E|)$ on the nanometer scale. This LSPR-induced near-field interaction is called "electric near-field enhancement" (ENFE). This enhancement effect is affected by the spatially non-homogeneous distribution of plasmons on nanomaterials and attenuates exponentially within the spacing range of 10 - 50 nanometres away from the metal surfaces, relying on the size, shape, and dielectric environments. ${ }^{8}$ The near-field enhancement factor $\left(|\mathrm{E} /| \mathrm{E}_{0} \mid\right)$ can be as large as $10^{3}$ at the surface of individual nanoparticles, whereas it can reach $10^{6}$ at the junction of interparticles, as shown in Fig. 4 with Agbeing being examples.
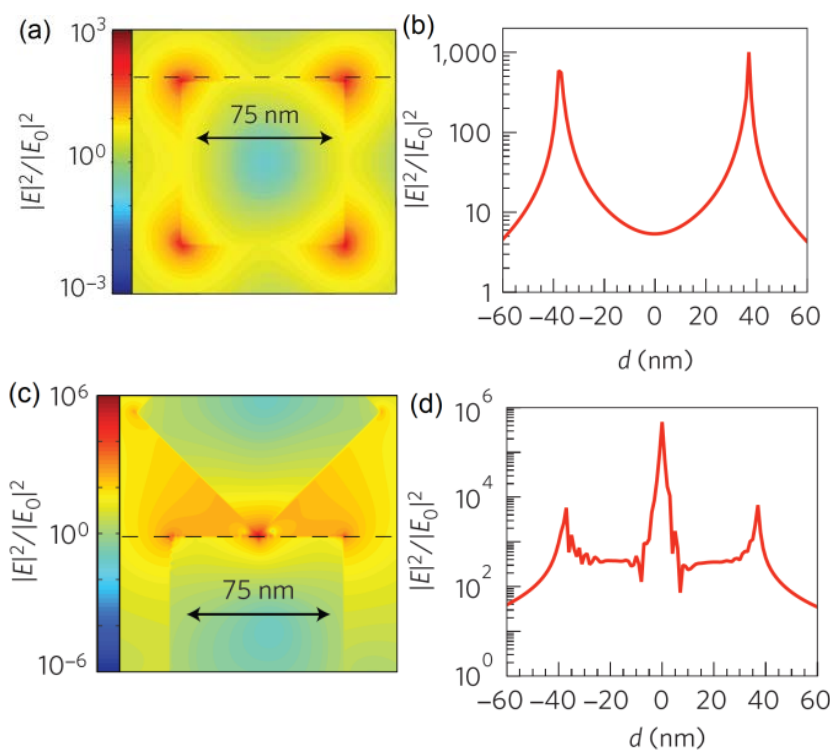

Fig. 4 Results of FDTD simulation (Finite-Difference TimeDomain): (a) distribution of the enhanced electric field intensity at the LSPR peak wavelength $(420 \mathrm{~nm})$ around a $75 \mathrm{~nm} \mathrm{Ag}$ nanocube; (b) quantified electric field intensity as a function of distance, $d$, along the dashed line indicated in (a); (c) distribution of the electric field intensity between two $75 \mathrm{~nm} \mathrm{Ag}$ nanocubes separated $1 \mathrm{~nm}$ away (one cube is rotated 45\%); (d) quantified value of electric field intensity as a function of dashindicated $d$ in (c). Reproduced with permission from Ref. ${ }^{8}$

The nanogap regions where the maximum ENFE occurs are referred to as "hot spots", playing a critical role in modifying the physiochemical, optical and reactive properties of catalysts. Thus, the enhancement effect has been successfully applied in surface-enhanced Raman scattering (SERS), sensitive photodetection, ${ }^{31}$ heatassisted magnetic recording, ${ }^{32}$ and photovoltaic solar cells. ${ }^{33}$ In photocatalysis, Awazu and co-workers embed Ag NPs in $\mathrm{TiO}_{2}$ particles to degrade the methyl blue, showing that the electric near-field amplitude on the surface of Ag NPs affords better catalytic performance. ${ }^{34}$ In our previous study, Au NPs are supported on zeolites to catalyse the acetalisation of benzaldehyde and 1pentanol, this reaction is originally catalysed by the protonic acid sites of zeolites, and it is discovered that the LSPR-induced ENFE can improve the catalytic performances. ${ }^{35,36}$ Experimental and DFT calculation results show that this enhancing effect is due to the elongation of $\mathrm{C}=\mathrm{O}$ bonds of the reactant benzaldehyde in 
the strengthened electric near field, thereby facilitating its breakage in the following reactions.

\subsubsection{Shottky barrier and charge separation}

For conventional semiconductor photocatalysts, at present, the limited photo absorption and the low apparent quantum efficiency (AQE) are two major bottlenecks for their large-scale industrial applications. ${ }^{37}$ The former is determined by the inherent energy band structure of a semiconductor, and the latter is mainly caused by the recombination of photo-generated charge carriers. To improve their photocatalytic performances, nanostructured metal co-catalysts play an indispensable role in fundamentally boosting the performance of semiconductor photocatalysts, particularly the $\mathrm{TiO}_{2}$ based nanomaterials. Researchers have been arguing that deposited metal nanostructures is involved in multiple crucial roles like: (i) they serve as passive electron sink with high capacity to store electrons to suppress photogenerated charge carrier recombination; (ii) they facilitate rapid dioxygen reduction to generate reactive free radicals; (iii) visible light response for $\mathrm{TiO}_{2}$-based photocatalysts can be achieved through the LSPR effect; (iv) direct excitation of metal nanoparticles especially under visible light and vectorial electron transfer to the conduction band of semiconductors. The mechanism (i) is widely accepted that there exists "Shottky barrier" at the "metal-semiconductor interface". Several review papers are well-documented on the subject of Shottky barrier between plasmonic metals and semiconductors; ${ }^{18}$, 38, 39 here a brief introduction on this is provided to help readers grasp the framework of plasmonic effects on modifying semiconductor photocatalysts.

As illustrated in Fig. 5, a redistribution of charge occurs owing to the overlap of the wave functions from the two sides at the "metal-semiconductor interface". Within this system, the parameter $\Phi_{M}$ is the working function of the metal, which is defined as the energy needed to bring an electron from the metallic Fermi energy to the vacuum. $\mathrm{X}_{\mathrm{SM}}$ is the electron affinity, the energy difference between the minimum conduction band (CB) and the vacuum (Vac) energy. Usually metals have lower Fermi energies ( $E_{\text {Fermi }}$ ) compared to those of semiconductors. Preferably, if the metal and semiconductor are connected, based on the stability, the direction of electron flow will be from the semiconductor to the metal and will continue until the $E_{\text {Fermi }}$ of the semiconductor reaches equilibrium with that of the metal, leading to a constant value of $E_{\text {Fermi }}$ for both sides. Due to this deformation of band structure between the semiconductor and the metal, a potential barrier is formed. The electrons (of the semiconductor) must overcome that barrier in order to flow from the semiconductor to the metal. This will cause a depletion of electrons at the semiconductor interface. The formation of a depletion zone causes the bending of valence band (VB) and conduction band (CB) of semiconductor for example in an n-type semiconductor the bands are shifted downwards and p-type semiconductors the bands are bent upwards in relation to the Fermi level. ${ }^{40}$

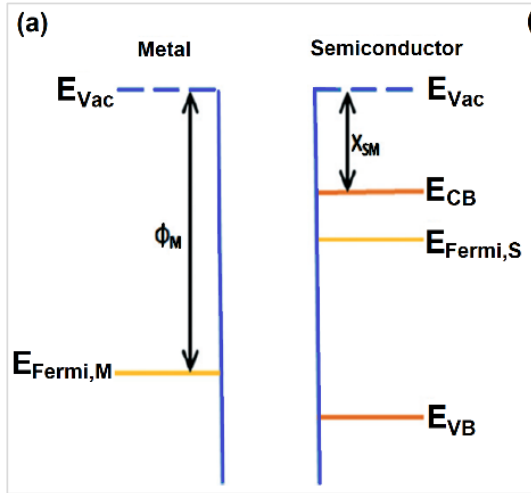

(b)

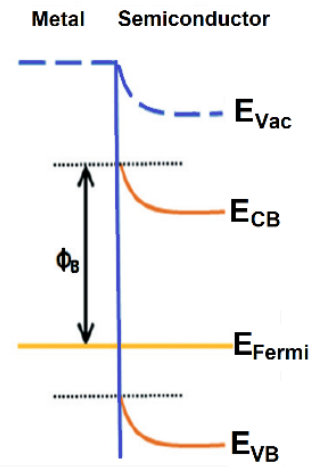

Fig. 5 Scheme of the Formation of Schottky barrier between ntype semiconductors and metals (a) before contact and (b) after contact. Reproduced with permission from Ref. ${ }^{38}$

This band bending or the Schottky barrier $\left(\Phi_{\mathrm{B}}\right)$ can be expressed by the following equation: $\Phi_{\mathrm{B}}=\Phi_{\mathrm{M}}-\mathrm{X}_{\mathrm{SM}}$. In parallel, the transfer of the accumulated photo-excited electrons from the CB edge of the semiconductor to the metal deposit is facilitated when the band edge positions of both match with each other, but the opposite scenario is prevented to certain extent by the thus-formed formation of Schottky barrier. ${ }^{41}$ The interaction of the CB electrons with the electromagnetic field of specific wavelengths in the nanometal deposits causes coherent electron cloud oscillations leading to the increase in the energy density at the surface. Thus, noble metal nanoparticles immobilised on the semiconductor surface can enhance the local field energy under visible light excitation through the SPR effect and then these electrons participate in the photocatalytic redox reactions or in the energy conversion process. ${ }^{42}$ The plasmon absorption band of metal deposited $\mathrm{TiO}_{2}$ will be generally observed at higher wavelengths compared to the unmodified $\mathrm{TiO}_{2}$. Interfacial and interparticle interactions dictate the shift and broadening of plasmon band of metal nanoparticles deposited on the $\mathrm{TiO}_{2}$ surface. $^{43}$ 


\subsection{Au, Ag, Cu-based nanostructures with metal dopants, promoters, or co-catalysts}

Besides size- and shape-dependence of plasmonic nanostructures, the properties of plasmonic nanometals can be further modified by incorporating more than one metallic or non-metallic component into a common nanoparticle to form, for example, a bimetallic or alloy nanoparticle. ${ }^{44,45}$ It has also been confirmed that cooperative and synergistic interactions between the metallic components could lead to an overall more useful functionality. The bimetallic nanoparticles may be fabricated as alloy nanoparticles in which the two constituent metals are homogeneously mixed at the atomic level, or they form core-shell composite nanoparticles where the two components are separated by distinct phase boundaries. In addition, it is known that bimetallic nanoparticles with the same overall composition but different composition distributions can exhibit different properties. The geometric distribution of the metals within a particle between the two extremes of alloy (maximally mixed) and core-shell (minimallymixed) nanoparticles may therefore be used to increase the versatility in property tuning. In an effort to extend the envelope of possibility further, researchers already demonstrate the synthesis of various $\mathrm{Au}-$, Ag-, or $\mathrm{Cu}-$ based plasmonic photocatalysts combining other dopants, promoters or co-catalysts, with Ag, Pt, Pd and semiconductors being popular examples.

\subsubsection{Au-Ag and Au-Cu, Ag-Cu combination}

Au-Ag alloy and bimetallic core-shell structures and their mutual transformation are mostly investigated. ${ }^{46,47}$ Growth or deposition of Au NPs on Ag nanostructures as "supports" can achieve tunable plasmonic properties comparable to the original $\mathrm{Au}$ or Ag nanostructures. ${ }^{48,49}$ On the other hand, Au(core)-Ag(shell) nanostructures are also synthesised and can be transformed to AuAg alloy by annealing treatment. ${ }^{30} \mathrm{~A}$ more complexed structure of Ag core and AgAu alloy shell (Ag@AgAu) was also developed and the alloy shell composition can be tuned by the replacement reaction between Ag NPs and $\mathrm{HAuCl}_{4}$, using small $\mathrm{Ag} \mathrm{NPs}$ as the sacrificial templates (Fig. 6); ${ }^{30}$ Recent studies demonstrate the synthesis of Ag@AgAu nanoframes (Fig. 7(L) ${ }^{50}$ ) and Au@AgAu nanorattles (Fig. 7(R). ${ }^{\mathbf{5 1}}$ )

AuAg alloy nanoparticles have also been employed to modify $\mathrm{TiO}_{2}$ based to improve the photo response or light absorption. Verbruggen and co-workers developed $\mathrm{Au}_{\mathrm{x}} \mathrm{Ag}_{1-\mathrm{x}}$ plasmonic $\mathrm{TiO}_{2}$-based photocatalysts with a visible light response that can be accurately tuned over a broad range of the spectrum, thus offering a possibility to maximise the spectral response for solar to chemical energy conversion. ${ }^{52,53}$
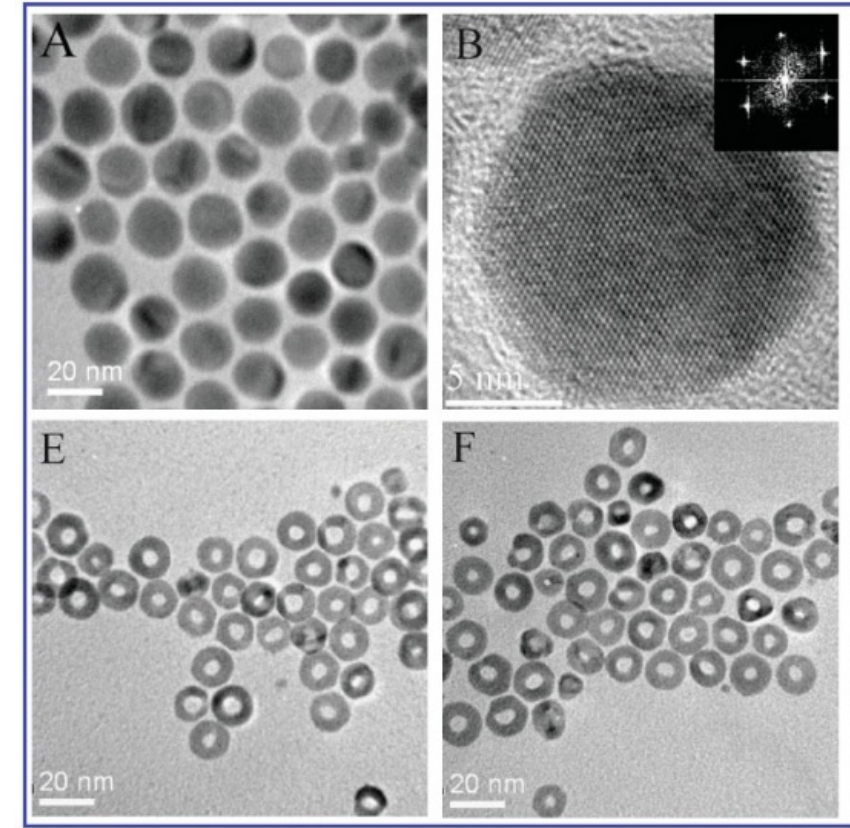
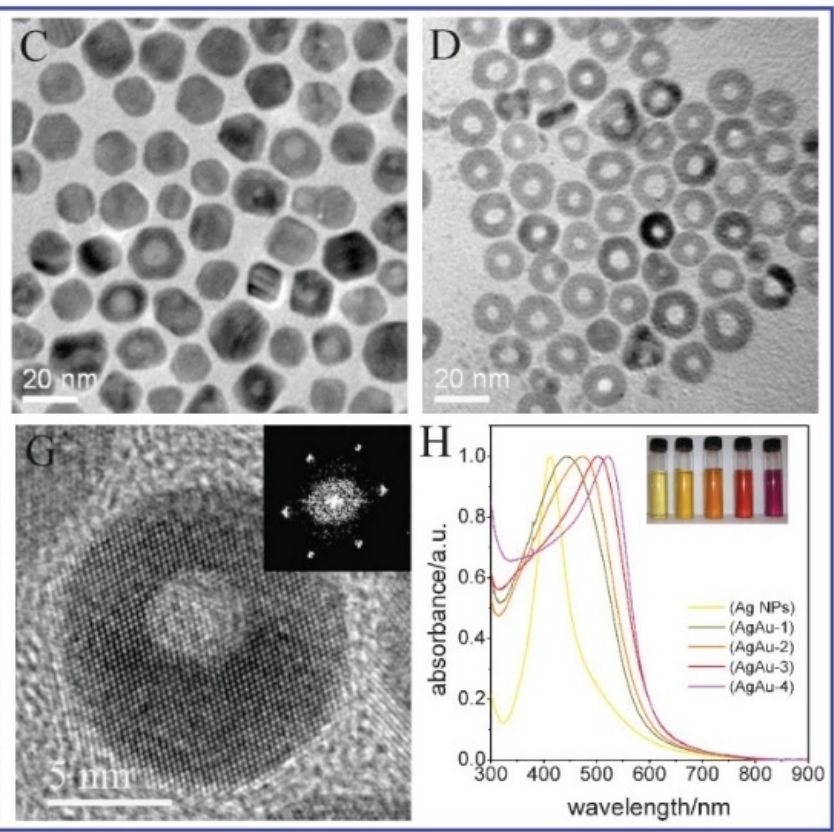

Fig. 6 (A) TEM image of the Ag NP seeds; (B) HRTEM image of a starting Ag NP; the inset shows the corresponding diffractogram; (C-F) TEM images of AgAu-1 to AgAu-4 nanoparticles; (G) HRTEM image of a AgAu-3 nanoparticle; the inset is the corresponding diffractogram; (H) normalised absorbance spectra of Ag NPs and AgAu-1 to AgAu-4 nanoparticles; the inset shows the corresponding digital photos. Reproduced with permission from Ref. ${ }^{54}$ 

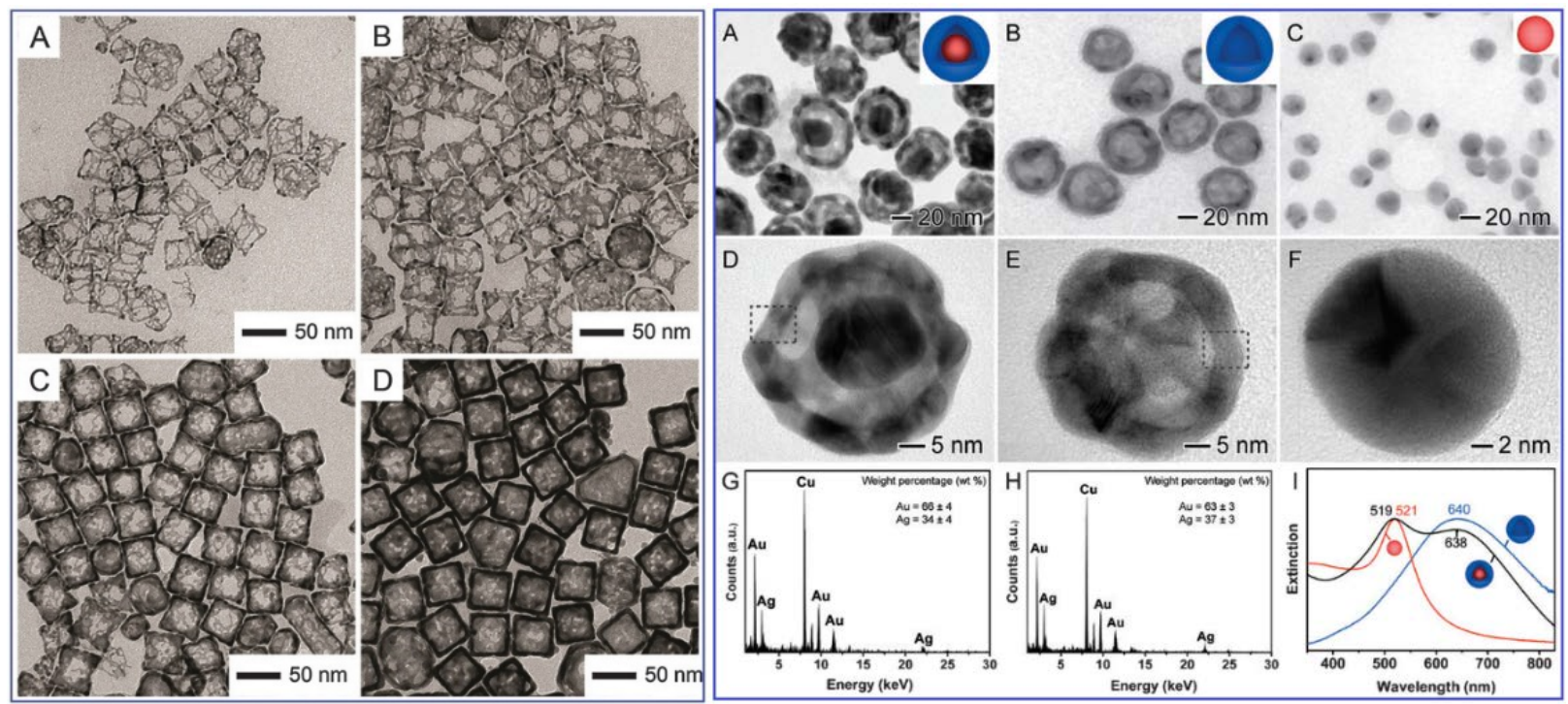

Fig. 7 (Left group) TEM images of $\mathrm{Ag@Ag-Au} \mathrm{core-frame} \mathrm{nanocubes} \mathrm{after} \mathrm{etching} \mathrm{with} 3 \%$ aqueous $\mathrm{H}_{2} \mathrm{O}_{2}$. The samples were prepared by co-titrating different volumes of aqueous $\mathrm{AgNO}_{3}(0.3 \mathrm{mM})$ and $\mathrm{HAuCl}_{4}(0.1 \mathrm{mM}):(\mathrm{A})$ 0.2, (B) $0.4,(\mathrm{C}) 0.8$, and (D) $1.5 \mathrm{~mL}$ for each precursor. Reproduced with permission from Ref. ${ }^{50}$ (Right group) (A-C) TEM and (D-F) HRTEM images for Au@AgAu nanorattles (A and D), AgAu nanoshells (B and E), and Au NPs (C and F). The EDX spectra from the regions indicated by black dashed squares in (D) and (E) are shown in (G) and (H), respectively. (I) Normalised UV/Vis extinction spectra recorded from aqueous suspensions containing Au@AgAu nanorattles, AgAu nanoshells and Au NPs (black, blue, and red traces, respectively). Reproduced with permission from Ref. ${ }^{51}$

The combination of $\mathrm{Au}$ and $\mathrm{Cu}$ not only reduce the cost of catalysts but also offers more opportunities to develop new photocatalysts. He and co-workers developed an aqueous phase route to synthesise pentacle $\mathrm{Au}-\mathrm{Cu}$ alloy nanocrystals with fivefold twinning, the size of which can be tuned in the range from 45 to $200 \mathrm{~nm}$ as shown below in Fig. 8..$^{55}$ In another study, Ag-Cu alloy was examined in the selective reduction of nitroaromatics to azoxy compounds. ${ }^{56}$ The ration between two metal content shows little effect on the product selectivity. Nevertheless, these studies demonstrate a potential method to combine $\mathrm{Au}$ and $\mathrm{Cu}$, which is a promising way to reduce the cost of catalysts and ameliorate the instability of copper in some certain reactions.
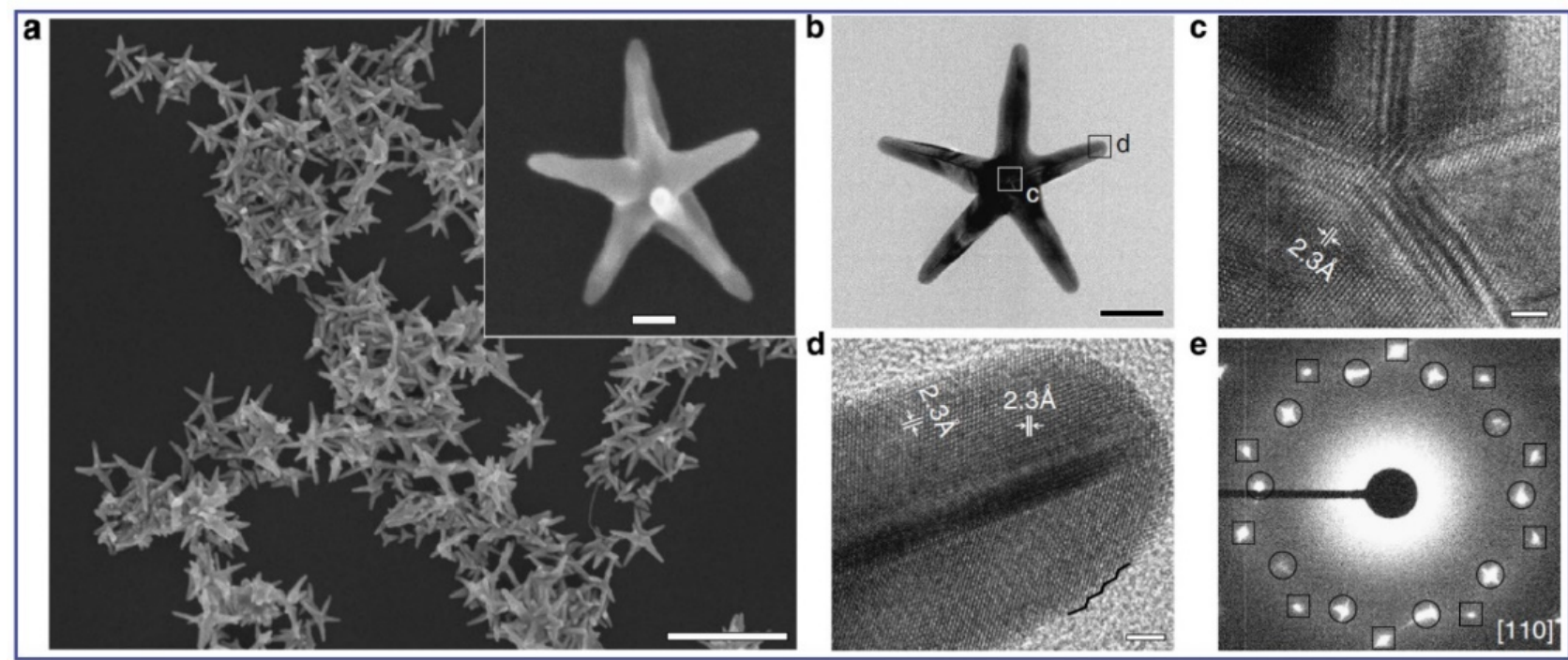

Fig. 8 Structure and composition study of pentacle Au-Cu alloy nanocrystals. (a) SEM image of the pentacle nanocrystals prepared through the standard procedure. The inset shows a SEM image of a typical individual nanocrystal. (b) TEM image of an individual pentacle Au-Cu alloy nanocrystal. (c,d) HRTEM images of the parts marked in b. (e) The corresponding selected-area electron diffraction pattern with the electron beam directed along the fivefold axis. The circles correspond to electron diffractions from the $\{111\}$ planes while the boxes correspond to those from the $\{200\}$ planes. Reproduced with permission from Ref. ${ }^{55}$ 


\subsubsection{Au-Pt and Au-Pd combination}

Pt-based bimetallic nanoparticles with noncompact nanobranches show great potential as catalysts for reducing Pt consumption, providing a high surface area and facilitating the enhanced performance in the catalytic applications (Fig. 9). the surface plasmonic resonance peak of the Au core can be observed even when many Pt nanobranches are supported on the Au core because of the noncompact Pt nanobranches, which is important for in situ spectroscopic (such as surfaceenhanced Raman scattering) characterisation of catalytic reactions. ${ }^{57}$ In addition, bimetallic dendritic platinum decorated gold nanorods has also been developed by the spatial control of Pt growth over gold nanorods using a heterogeneous seed-mediated growth method. ${ }^{58}$ In this structure, as shown in Fig. 10, Pt nanostructures were spatially separated from each other, which was highly favorable for promising optical and catalytic properties, and thus the dendritic-Pt decorated Au nanorods with variable $\mathrm{Au} / \mathrm{Pt}$ ratios have the potential to tune their surface plasmonic properties and catalytic capacity.

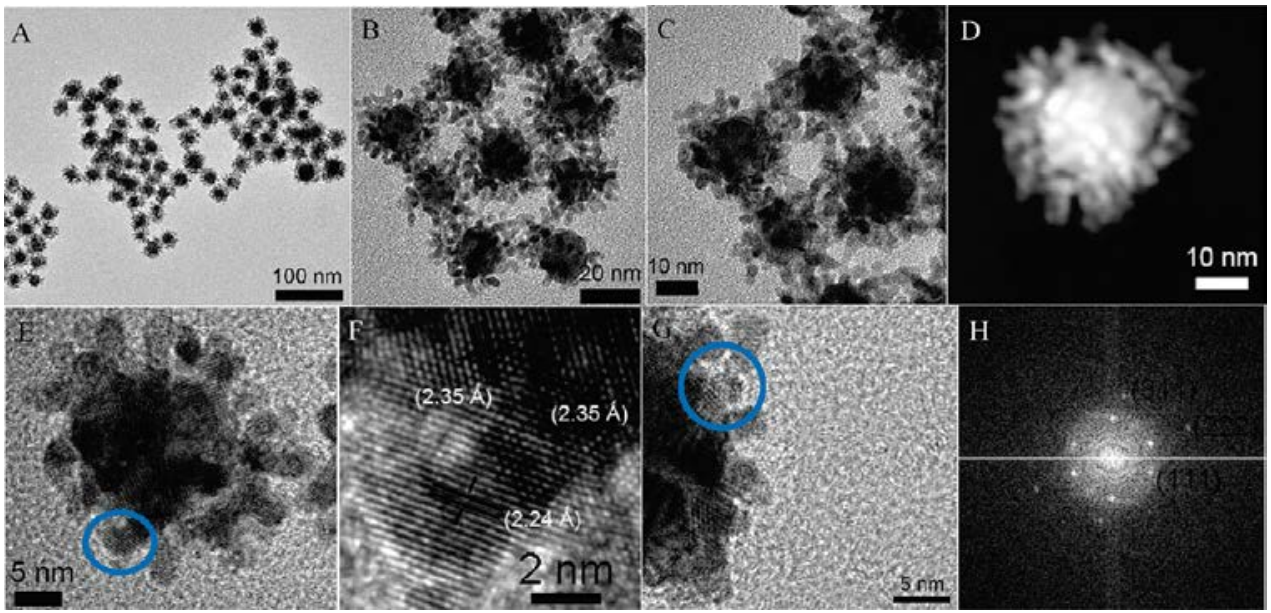

Fig. 9 TEM (A-C), HAADF-STEM (D), and HRTEM (E-G) images of Bimetallic dendritic NPs with noncompact nanobranches (denoted as BDNNNs). Panel (H) shows the fast Fourier transform (FFT) of panel G (circled part). Reproduced with permission from Ref. ${ }^{57}$

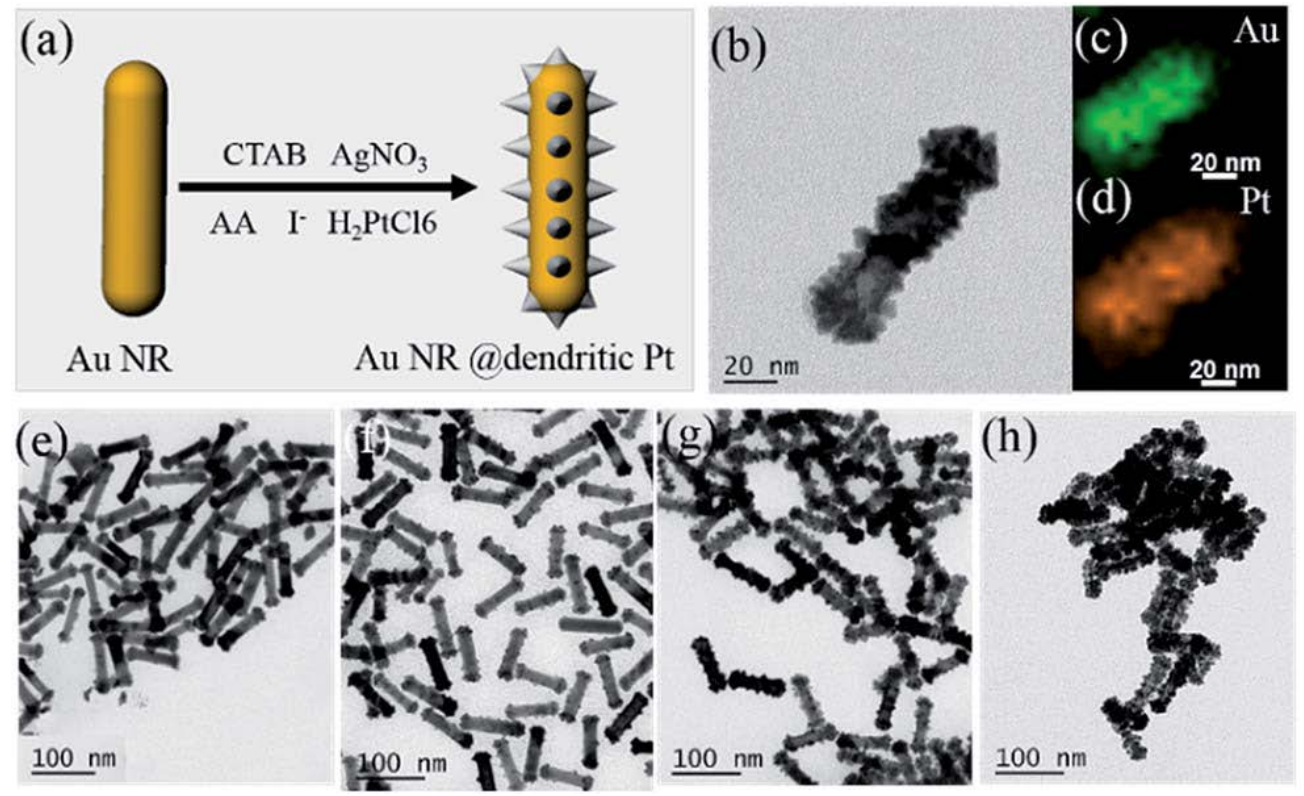

Fig. 10 (a) Scheme of the synthesis of dendritic-Pt decorated AuNRs (NRs = nanorods); (b) TEM images of dendritic-Pt decorated AuNRs. (c) and (d) Show the elemental mappings of one dendritic-Pt decorated AuNRs. The green and orange colours in the elemental maps stand for gold and platinum, respectively; TEM images (e-h) of nanostructures with varying volume fractions dendritic platinum obtained by adding different amounts of a $2 \mathrm{mM} \mathrm{H}_{2} \mathrm{PtCl}_{6}$ solution: (e) $55 \mathrm{~mL}$, (f) $110 \mathrm{~mL}$, (g) $220 \mathrm{~mL}$ and (h) $440 \mathrm{~mL}$, respectively. Reproduced with permission from Ref. ${ }^{58}$ 
Since Au-Pt nanostructures possess unique optical and catalytic properties, it is reasonable to combine them with conventional semiconductor photocatalysts to construct composite photocatalytic nanomaterials with adjustable photocatalytic capacity. Au/Pt-co-decorated $\mathrm{TiO}_{2}$ nanofibers have been shown to have remarkably enhanced photocatalytic activities on both hydrogen generation and $\mathrm{CO}_{2}$ reduction. ${ }^{59}$ The $\mathrm{Au}$ and Pt NPs were synthesised with sizes of 5-12 nm and the authors deduce that the enhancement in photocatalytic performances are due to the electron-sink function of $\mathrm{Pt}$ and the surface plasmon resonance of Au NPs, which significantly improves charge separation of photoexcited $\mathrm{TiO}_{2} . \mathrm{TiO}_{2}$ nanosheets have also been co-loaded with Au-Pt nanoparticles by a photo-deposition method and applied in the $\mathrm{H}_{2}$ evolution, which illustrates the synergistic effect between the plasmonic enhancement of $\mathrm{Au}$ and the co-catalysis of $\mathrm{Pt}^{60}$ In addition, $\mathrm{TiO}_{2}$ nanopillar arrays are also used to load $\mathrm{Au} / \mathrm{Pt}$ through successive ion layer adsorption and reaction, and this composite photocatalysts exhibit a photocatalytic reaction efficiency which is 21 and 13 times higher than that of pure $\mathrm{TiO}_{2}$ sample under $\mathrm{UV}-\mathrm{Vis}$ and visible light, respectively. ${ }^{61} \mathrm{Au}$, Pt loaded $\mathrm{WO}_{3}$ was combined by using colloid photo-deposition of Au particles on $\mathrm{WO}_{3}$ followed by photo-deposition of Pt particles onto $\mathrm{Au}$ particles, a $\mathrm{Pt} / \mathrm{Au} / \mathrm{WO}_{3}$ sample was thus prepared. The $\mathrm{Pt} / \mathrm{Au} / \mathrm{WO}_{3}$ sample continuously yielded $\mathrm{H}_{2}$ and $\mathrm{CO}_{2}$ from glycerin under visible light irradiation. ${ }^{62}$ The authors distinguished the contribution of the action spectrum under additional irradiation by light from the blue LED or green LED and clarified that both the bandgap excitation of $\mathrm{WO}_{3}$ and the surface plasmon resonance of $\mathrm{Au}$ NPs simultaneously contribute to $\mathrm{H}_{2}$ formation.

$\mathrm{Au}$ and Pd combination is another way to attenuate the LSPR effect. ${ }^{63}$ AuPd nano-wheels have been developed by a facile wet-chemical reduction method with a controllable edge length and tunable LSPR features, as shown in Fig. 11. ${ }^{64}$ These AuPd nanowheels served as highly efficient catalysts in the oxidation of benzyl alcohol and a Suzuki coupling reaction under irradiation with light with much enhanced performance being observed compared to that under conventional heating conditions.

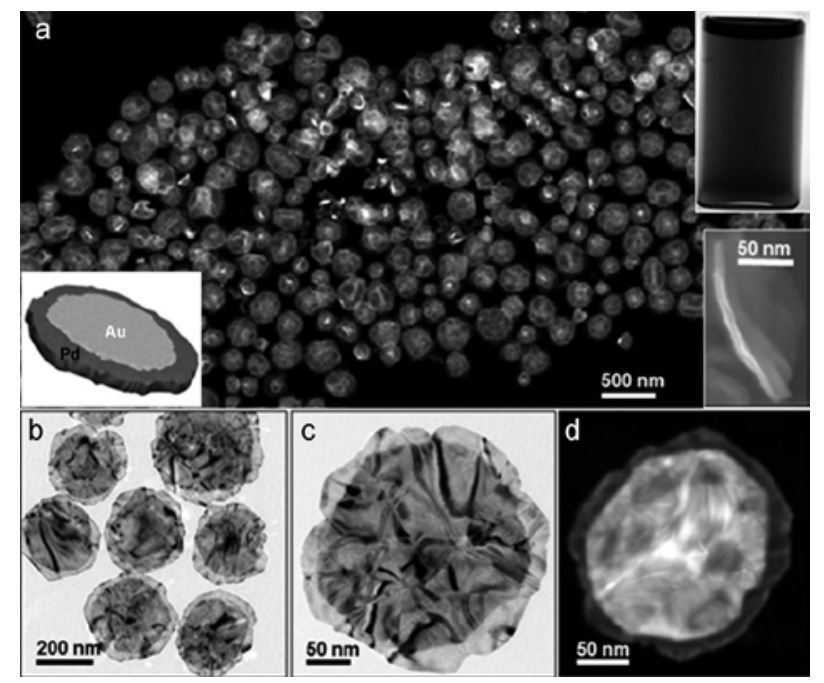

Fig. $11(\mathbf{a}, \mathbf{b})$ Selected low-magnification HAADF-STEM (a) and TEM images (b) of the as-prepared AuPd nanowheels. (c,d) High magnification TEM (c) and HAADF-STEM images (d) of an individual AuPd nanowheel. The bottom-right inset in (a) shows an SEM image of an individual AuPd nanowheel viewed from the side. The bottom-left inset in (a) shows an ideal model of a AuPd nanowheel. The top right inset in (a) shows a photograph of a dispersion of the AuPd nanowheels in water in a glass vial. Reproduced with permission from Ref. ${ }^{\mathbf{6 4}}$

Palladium (Pd) is well-known to be catalytically active for many reactions of important organic syntheses, and various approached have been developed to manipulate the intrinsic catalytic properties of Pd through such as doping and alloying another element. Supported AuPd alloy nanoparticles on such as $\mathrm{Al}_{2} \mathrm{O}_{3}, \mathrm{ZrO}_{2}, \mathrm{TiO}_{2}$ and hydrotalcites as plasmonic photocatalysts have been reported in some studies. AuPd/ $\mathrm{Al}_{2} \mathrm{O}_{3}$ was tested in the visible light assisted $\mathrm{CO}_{2}$ reduction with methane (CRM), and the authors demonstrated that the plasmonic absorption in visible light region and the electromagnetic field induced by hot electrons were enhanced in $\mathrm{Au}-$ containing $\mathrm{Pd}_{x} \mathrm{Au}_{y}$ alloys, which facilitated $\mathrm{CO}_{2}$ activation to oxygen radical and was regarded to be responsible for further accelerating the reaction rate. And they also claim that increasing the content of $\mathrm{Au}$ in the $\mathrm{Pd}_{\mathrm{x}} \mathrm{Au}_{\mathrm{y}}$ alloys, the electronic structure of Pd could be gradually tuned to electron-deficient, which favored the stability of the $\mathrm{Pd}_{x} \mathrm{Au}_{\mathrm{y}} / \mathrm{Al}_{2} \mathrm{O}_{3}$ catalysts in thermaldriven CRM with partially reduced activities. ${ }^{65}$ Supported AuPd alloy nanoparticles on $\mathrm{ZrO}_{2}$ were investigated to enhance the conversion of several reactions, including Suzuki-Miyaura cross-coupling, oxidative addition of benzylamine, selective oxidation of aromatic alcohols to corresponding aldehydes and ketones, and phenol oxidation. ${ }^{66,67}$ They found that the intrinsic catalytic activity of palladium (Pd) is 
significantly enhanced in gold (Au)-Pd alloy nanoparticles (NPs) under visible light irradiation at ambient temperatures and that the $\mathrm{Au} / \mathrm{Pd}$ molar ratio of the alloy NPs has an important impact on performance of the catalysts since it determines both the electronic heterogeneity and the distribution of Pd sites at the NP surface, with these two factors playing key roles in the catalytic activity.

These aforementioned studies regarding AuPd on a support look into only the plasmonic contributions of AuPd alloy, regardless of the effect of supports. For many cases, the influence of supports is not negligible, particularly when the supports are catalytic materials themselves such as $\mathrm{TiO}_{2}$, zeolites, and hydrotalcites. For these reasons, some researchers combine AuPd alloy or bimetallic with these "active" supports to investigate their photocatalytic properties. Xiao and co-workers developed phosphate-modified hydrotalcite $\left(\mathrm{HT}-\mathrm{PO}_{4}{ }^{3-}\right)$ to support AuPd alloy nanoparticles, and this unique structure can effectively couple the basic sites of the support material with the photocatalytic properties of the alloy nanoparticles, for the direct self-esterification of aliphatic alcohols under irradiation. ${ }^{68}$ Thus, the direct esterification of aliphatic alcohols can be driven without any additive (extra bases) under visible-light irradiation and benign reaction conditions. In other studies, AuPd alloy nanoparticles are combined with conventional $\mathrm{TiO}_{2}$ photocatalysts of " $\mathrm{TiO}_{2}(\mathrm{~B}) /$ anatase heterostructured nanobelt" as plasmonic photocatalysts for benzyl alcohol oxidation. ${ }^{69}$ The authors present that this inter-phase charge transfer through $\mathrm{TiO}_{2}(\mathrm{~B}) /$ anatase hetero-junction greatly facilitates the flow of "hot electrons" from the metal nanoparticles to $\mathrm{TiO}_{2}$ and promotes the oxidation efficiency. In addition, alloying $\mathrm{Au}$ with $\mathrm{Pd}$ in $\mathrm{Au}-\mathrm{Pd} / \mathrm{TiO}_{2}-\mathrm{NB}$ results in a significant enhancement in the visible light-promoted catalytic activity compared with the monometallic $\mathrm{Au} / \mathrm{TiO}_{2}-\mathrm{NB}$ sample, and this enhancement effect is associated with the plasmon-mediated charge distribution within the alloy NPs.

\subsubsection{Au, Ag, or Cu-combined with non-metallic partners}

Besides metallic dopants, promoter or co-catalysts, other nanomaterials such as metal oxides, semiconductors, zeolites, hydrotalcites and so on are often combined with plasmonic metals to prepare targeted photocatalysts. In these photocatalysts, the non-metallic partners are not only supports, but also serve as participants in reactions or as a tool to modify the catalyst structures.
Gold nanorods used as photosensitisers combined with $\mathrm{TiO}_{2}$ can harvest wide-range visible-light and enhance the catalytic capacity to oxidise 2-propanol. ${ }^{70} \mathrm{In}$ this design, five $\mathrm{TiO}_{2}$-supported Au nanorod catalysts were prepared by loading Au nanorods with different aspect ratios, and the surfactant was removed by the $\mathrm{HClO}_{4}$ oxidative method. As can be seen from Fig. 12a and b, well dispersed Au nanorods (bright rods) can be discerned from the background. In HRTEM image, Fig. 12c, Au nanorods with an aspect ratio of 2.3 as well as $\mathrm{TiO}_{2}$ crystals can be easily discerned. As shown in Fig. 12d, a close contact is formed at the interface of $\mathrm{Au}$ nanorods and $\mathrm{TiO}_{2}$, which would facilitate the electron or energy transfer in this composite photocatalyst. By adjusting the aspect ratio of $\mathrm{Au}$ nanorods, longitudinal plasmon resonance adsorptions are tuned from $630 \mathrm{~nm}$ to $810 \mathrm{~nm}$ (Fig. 12 e). Therefore, the adjustable light adsorption resulting from the tunability of gold nanorod aspect ratio would benefit to designing photocatalyst with specific light harvesting.
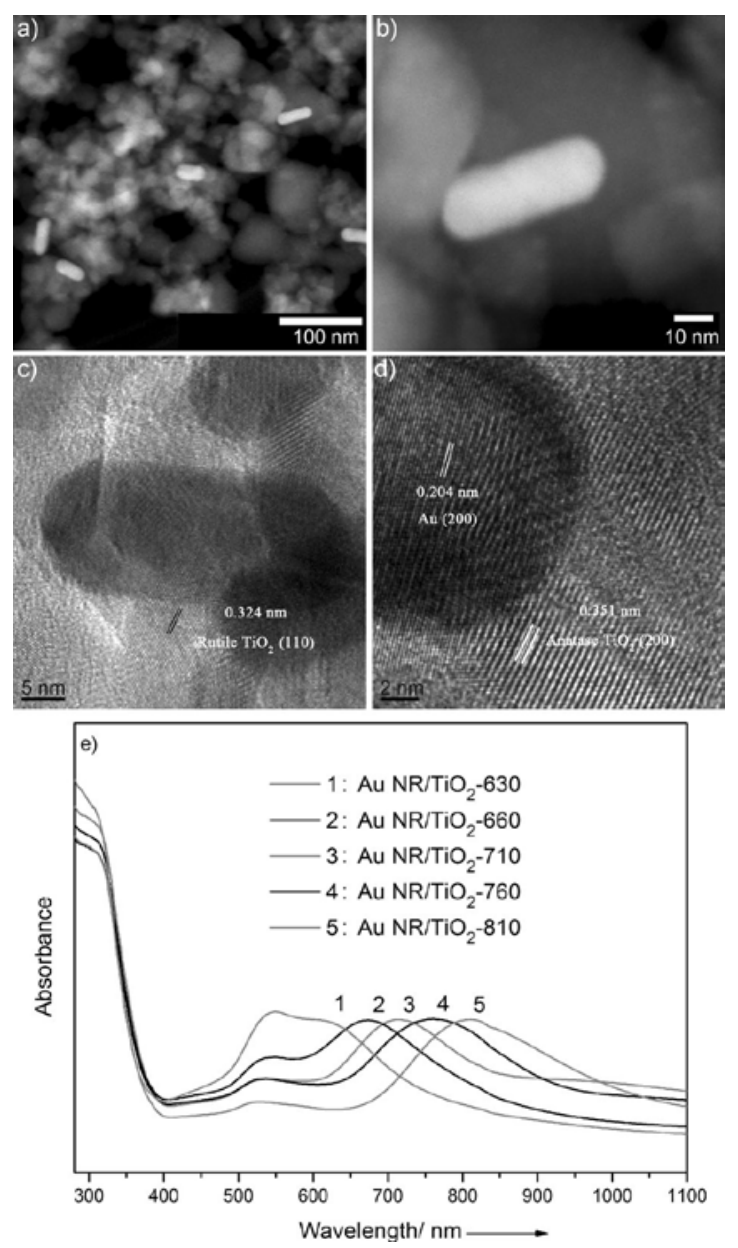

Fig. 12 (a,b) HAADF-STEM images and (c,d) HRTEM images of the AuNR/TiO $2-660$ (NR = nanorods) photocatalyst; (e) UV/Vis absorption spectra of $\mathrm{AuNR}_{\mathrm{TiO}}$ photocatalysts. Reproduced with permission from Ref. ${ }^{\mathbf{7 0}}$ 
$\mathrm{Au}$ NPs located at the interface of anatase/rutile $\mathrm{TiO}_{2}$ particles are used as active plasmonic photocatalysts for the aerobic oxidation of aromatic alcohols to aldehydes. $^{71}$ It is found that this photocatalysis is promoted via plasmon activation of the $\mathrm{Au}$ particles by visible light followed by consecutive electron transfer in the $\mathrm{Au} /$ rutile/anatase contact site. The activated $\mathrm{Au}$ particles transfer their conduction electrons to rutile and then to adjacent anatase $\mathrm{TiO}_{2}$. This catalyses the oxidation of substrates by the positively charged $\mathrm{Au}$ particles along with reduction of $\mathrm{O}_{2}$ by the conduction band electrons on the surface of anatase $\mathrm{TiO}_{2}$. Like the above-mentioned $\mathrm{Au}$ and bimetallic Au-Pd alloy nanoparticles loaded on one-dimensional $\mathrm{TiO}_{2}$ (B)/anatase hetero-structured nanobelts $\left(\mathrm{TiO}_{2}-\right.$ NBs). ${ }^{69}$ The difference in band structure and the well matched interface between the $\mathrm{TiO}_{2}(\mathrm{~B})$ and anatase phases, coupled with the one-dimensional nanostructure, enable an enhanced charge transfer within the heterostructured nanobelt, resulting in a significant improvement in the visible light-promoted activity compared to the monometallic $\mathrm{Au} / \mathrm{TiO}_{2}-\mathrm{NB}$ sample.

Through heterogeneous nucleation and growth, a method was developed for coating $\mathrm{CeO}_{2}$ on monometallic Au and bimetallic Au@Pt, Au@Pd nanocrystals to produce multifunctional core@shell nanostructures. ${ }^{72}$ Monodisperse (Au core)@(CeO ${ }_{2}$ shell) nanostructures with different $\mathrm{CeO}_{2}$ shell thicknesses and plasmon wavelengths from the visible to near-infrared region are obtained with its structures shown in Fig. 13. The Plasmon shifts of the (Au core)@ $\left(\mathrm{CeO}_{2}\right.$ shell) nanostructures resulting from the reversible switching between the Ce(IV) and Ce(III) states are observed. The photocatalytic test in the selective oxidation of benzyl alcohol to benzaldehyde, performed under both broadband and monochromatic light, demonstrates the visiblelight-driven catalytic activity and reveals the synergistic effect on the enhanced catalysis of the $\mathrm{Au} @ \mathrm{CeO}_{2}$ nanostructures.
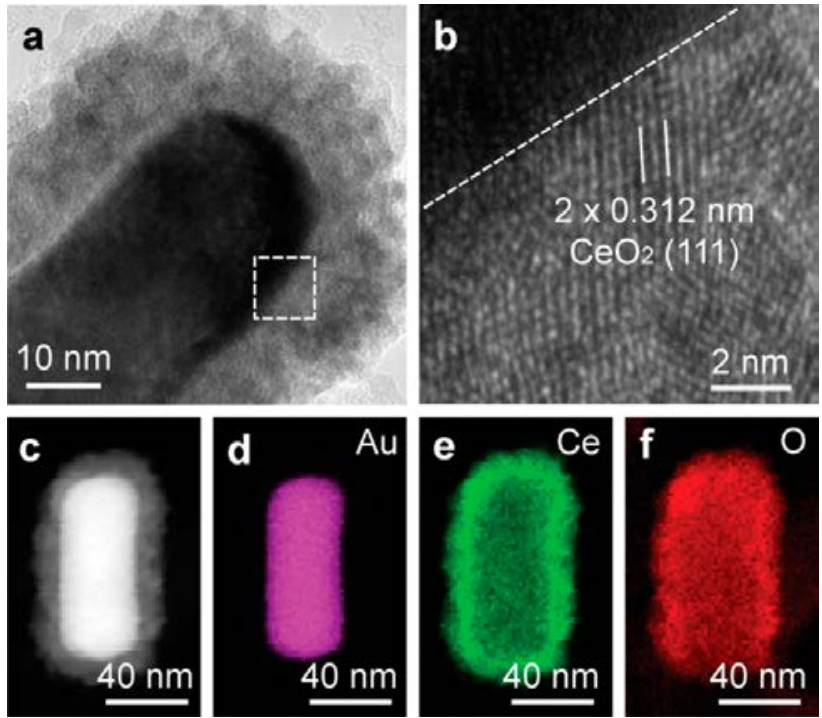

Fig. 13 Crystalline structure and composition of the asprepared (Au nanorod core)@( $\mathrm{CeO}_{2}$ shell) nanostructures. (a) TEM image taken at the end of a single core@shell nanostructure. (b) HRTEM image recorded from the area marked with a box in (a). The dashed line indicates the interface between $\mathrm{Au}$ and $\mathrm{CeO}_{2}$. (c) High-angle annular darkfield scanning transmission electron microscopy (HAADFSTEM) image of a single nanostructure. (d-f) Elemental maps of $\mathrm{Au}, \mathrm{Ce}$, and $\mathrm{O}$, respectively, on the nanostructure shown in(c). The Au nanorod sample used for coating is AuNR715. Reproduced with permission from Ref. ${ }^{72}$

Ag NPs supported on SBA-15 can show different colors and thus have different light absorptions as shown in Fig. $14(\mathrm{a} \rightarrow \mathrm{c}) \cdot{ }^{73} \mathrm{Ag} / \mathrm{SBA}-15$ was first synthesised by the microwave-assisted alcohol reduction method, which afforded color-controlled Ag NPs with different sizes and morphologies. Among them, the smaller yellowish Ag NPs exhibited the highest catalytic activity in $\mathrm{H}_{2}$ production from ammonia borane $\left(\mathrm{NH}_{3} \mathrm{BH}_{3}\right)$ under dark conditions, while the maximum enhancement under visible light irradiation was attained by blue $\mathrm{Ag}$ nanorods. Further decoration of Ag/SBA-15 with Pd NPs was achieved via localised surface plasmon resonance (LSPR)-assisted deposition under visible light irradiation. All Pd/Ag/SBA-15 catalysts showed higher catalytic activities than the inherent Ag/SBA-15 catalysts under both dark and visible-light irradiation conditions, where the $\mathrm{Pd} / \mathrm{Ag} / \mathrm{SBA}-15$ originated from blue Ag nanorods afforded a maximum enhancement effect. 


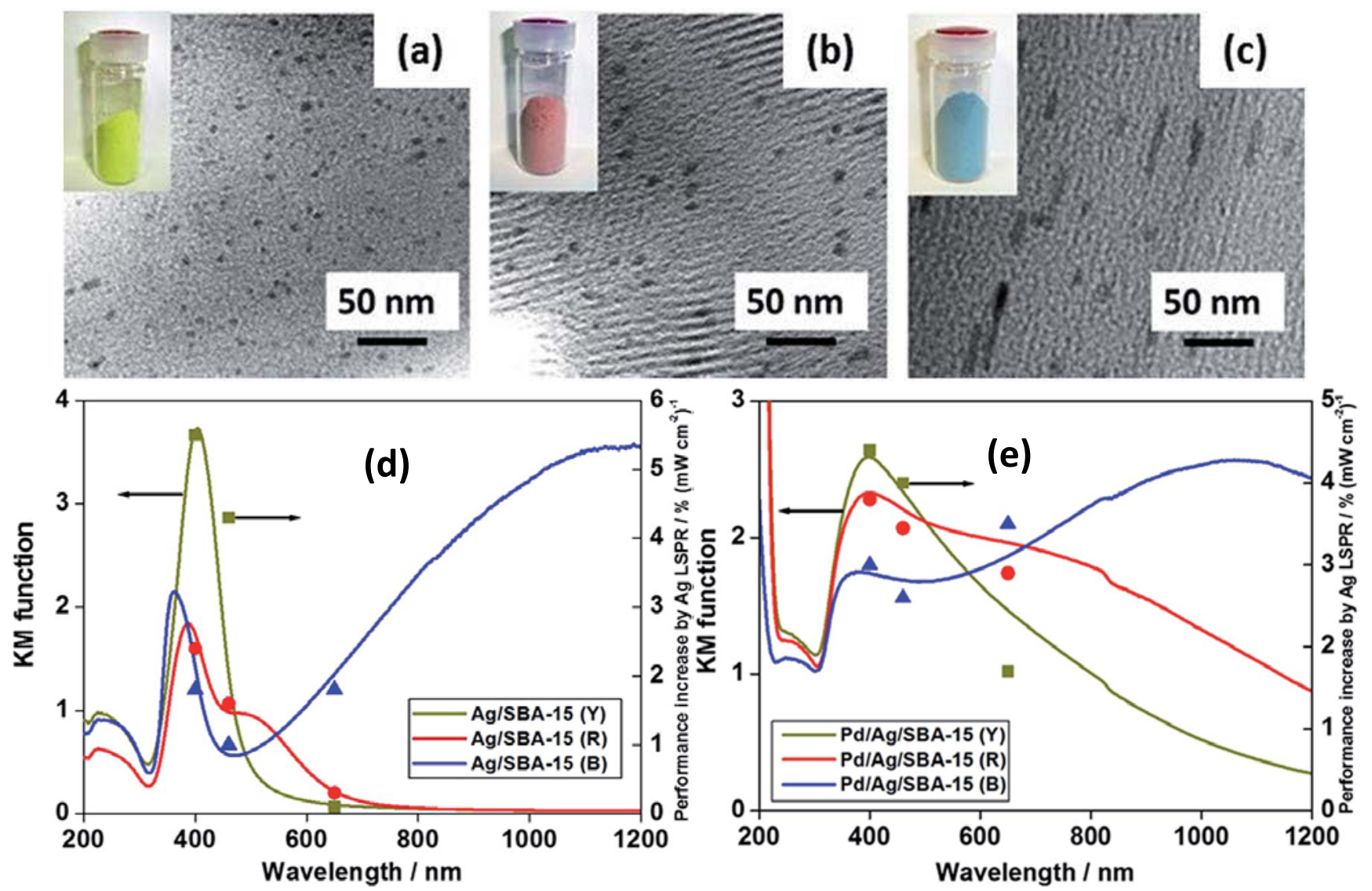

Fig. 14 (a-c) TEM images and sample photographs (inset) of (a) Ag/SBA-15(Y), (b) Ag/SBA-15 (R) and (c) Ag/SBA-15 (B). (d) UV-Vis spectra and wavelength dependence of the enhancement of catalytic activity of Ag/SBA-15 (Y), (R) and (B) under light irradiation of monochromatic light $(\lambda=400,460)$ and red LED $(\lambda \max =650 \mathrm{~nm})$. (e) UV-vis spectra and wavelength dependence of the enhancement of catalytic activity of $0.1 \mathrm{wt} \% \mathrm{Pd}$ deposited, $\mathrm{Pd} / \mathrm{Ag} / \mathrm{SBA}-15(\mathrm{Y}),(\mathrm{R})$ and $(\mathrm{B})$ under light irradiation by monochromatic light $(\lambda=400,460)$ and red LED $\left(\lambda_{\max }=650 \mathrm{~nm}\right)$. Reproduced from Ref. $^{73}$

\subsection{Pt, Pd, Rh-based photocatalysts}

$\mathrm{Pt}, \mathrm{Rh}$ and Pd and are three main metals that also show plasmonic effects. Therefore, like $\mathrm{Au}, \mathrm{Ag}$, or $\mathrm{Cu}$, they can act as a reservoir for photo generated electrons, promoting the interfacial electron transfer process and facilitating the photocatalytic reactions. On the other hand, they possess optical absorption response in the visible to infrared region of the spectrum due to coherent electron oscillation known as the LSPR. Platinum (Pt) has a plasmonic optical response and is commonly used as a catalyst in a variety of applications and sporadically employed as plasmonic photocatalysts or co-catalysts ${ }^{74,75,76}$. Rh also show the plasmonic effect, ${ }^{77}$ nevertheless, its utilisation as plasmonic photocatalysts is still unpopular probably due to their expensiveness and relatively weak or undetectable plasmonic effects in the visible light region. Compared with $\mathrm{Pt}$ and $\mathrm{Rh}, \mathrm{Pd}$ is more frequently investigated particularly in recent years.

Pd nanostructures can function both as broadband light absorbers whose plasmonic absorptions cover much of the solar spectrum. Ultrathin freestanding $\mathrm{Pd}$ nanosheets have been shown to have a tunable surface plasmon resonance peak in the near-infrared region and exhibit different edge lengths prepared under different conditions, and these hexagonal nanosheets display a size-dependent optical properties, as shown in Fig. 15. ${ }^{78}$ 

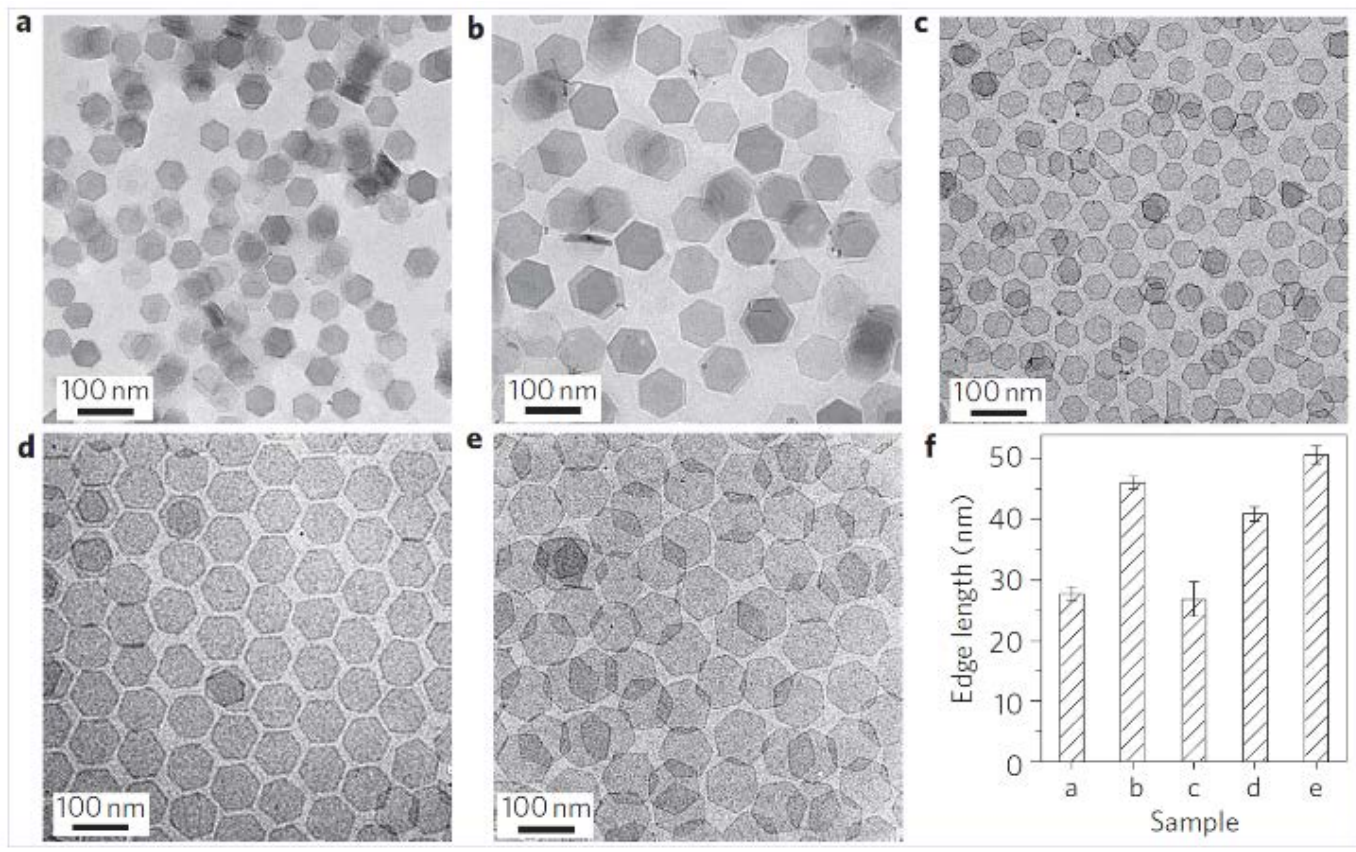

Fig. 15 TEM images of the Pd nanosheets produced under different reaction conditions (a-e) and their edge length (f). Reproduced with permission from Ref. ${ }^{78}$

In $\mathrm{Wu}$ and co-workers' study, Pd nanosheets and nanocubles as photocatalysts were compared in the dehydrogenating formic acid to $\mathrm{H}_{2}$ and $\mathrm{CO}_{2}$ in acidic media. ${ }^{79}$ The plasmonic effect strongly increases the room-temperature catalytic activity of both the Pd cube and sheet catalysts, as shown in Fig. 16. The nanosheet also benefits by a factor somewhat greater than 2, as a result of its broader absorption spectrum that includes the visible part of the spectrum, thereby covering most of the AM1.5 solar spectra.

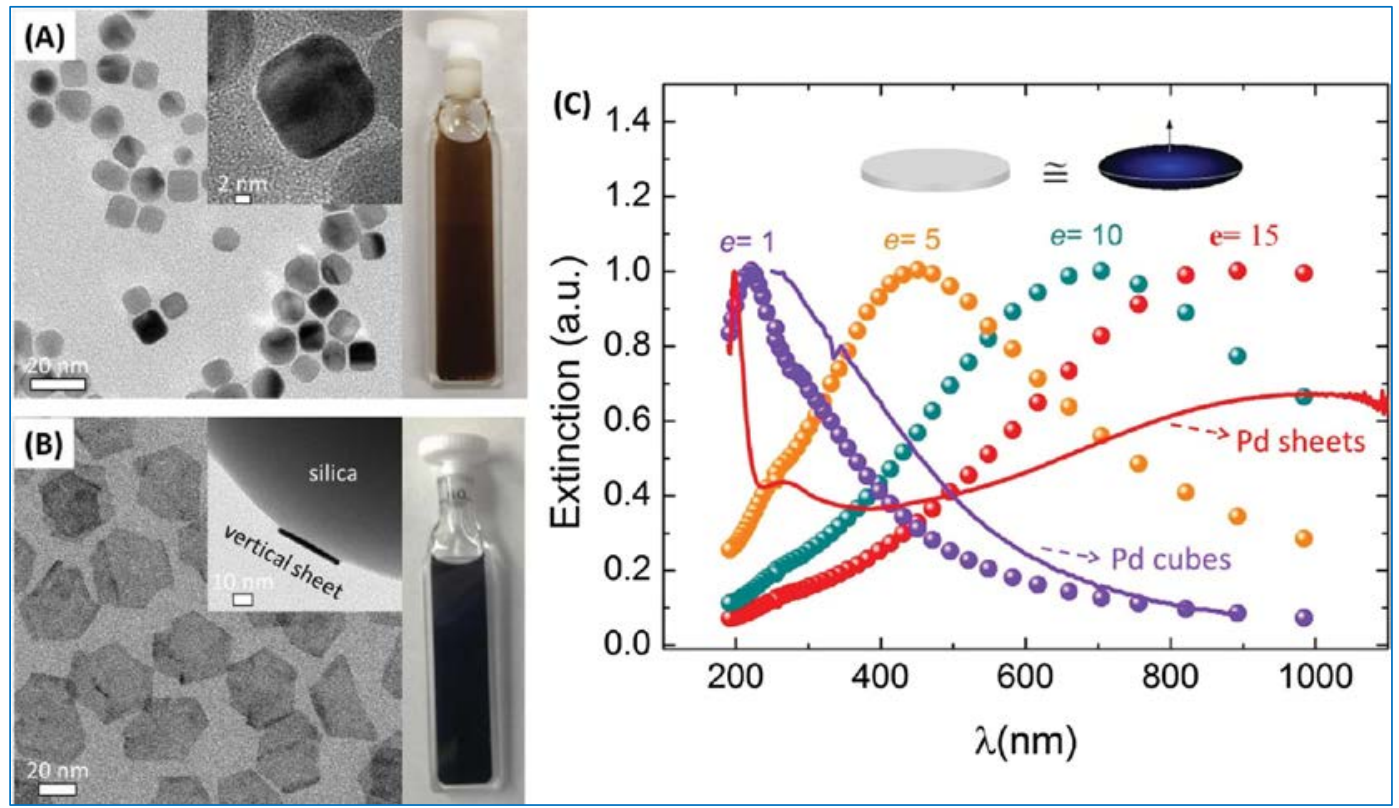

Fig. $16(A, B)$ TEM images of $\mathrm{Pd}$ nanocube and Pd nanosheet catalyst with their corresponding optical photographs of particles suspended in water. (C) Computed (dotted traces) and measured optical extinction spectra of Pd nanocubes (solid blue trace) and Pd nanosheets (solid red trace). The computations assumed that the extinction spectrum of the nanosheets could be credibly approximated by those of oblate spheroids of various eccentricities. The calculated $e=1$ spectrum is for a spherical nanoparticle which corresponds closely to what was measured for $\mathrm{Pd}$ nanocubes. The value $e=15.3$ is approximately equal to the eccentricity of the $\mathrm{Pd}$ sheets that we use, and, indeed, the location of the plasmonic maximum in that extinction spectrum satisfactorily matches what is measured. Reproduced with permission from Ref. ${ }^{79}$ 
Pd combined semiconductor photocatalysts are also developed in applications such as $\mathrm{H}_{2}$ evolution and pollutants degradation. For instance, the $\mathrm{Pd}-\mathrm{TiO}_{2}$ metalsemiconductor hybrid system in which Pd nanocrystals enclosed by $\{100\}$ facets are deposited on $\mathrm{TiO}_{2}$ supports, shows that driven by the Schottky junction, the $\mathrm{TiO}_{2}$ supports can provide electrons for metal catalysts under illumination by appropriate light. Further examination by ultrafast spectroscopy revealed that the plasmonics of Pd may force a large number of electrons to undergo reverse migration from $\mathrm{Pd}$ to the conduction band of $\mathrm{TiO}_{2}$ under strong illumination, thus lowering the electron density of the Pd surface as a side effect. ${ }^{80}$ For another instance, $\mathrm{Pd}$ nanosheets combined with $\mathrm{TiO}_{2}$ hybrid works in enhancing $\mathrm{H}_{2}$ evolution, in which $\mathrm{Pd}$ serve as co-catalysts and supplier of the plasmonic effect to boost the evolution. ${ }^{81}$ As illustrated in Fig. 17, ultrathin Pd nanosheets are integrated with semiconductor $\mathrm{TiO}_{2}$ nanosheets for photocatalytic hydrogen evolution, which acts as a co-catalyst and plasmonic agent in ultraviolet and visible-near-infrared spectral regions, respectively. Owing to the unique twodimensional (2D) nanostructure, the Pd nanosheet cocatalyst realises the large $\mathrm{TiO}_{2}$-Pd interfacial area for electron transfer as well as a large Pd exposed area for reduction reactions, while the plasmonic Pd nanosheets offer strong vis-NIR light absorption for "hot" electron production as well as a large interfacial area for "hot" electron injection. As a result, the Pd nanosheets achieve improved photocatalytic activity in comparison with three-dimensional Pd nanotetrahedrons under both light irradiations. Besides $\mathrm{TiO}_{2}$, Pd doped $\mathrm{Bi}_{2} \mathrm{MoO}_{6}{ }^{82}$ and $\mathrm{Pd} / \mathrm{Fe}_{2} \mathrm{O}_{3} / \mathrm{BiVO}_{4}{ }^{83}$ were also studied as plasmonic photocatalysts in the degradation of phenol showed enhanced catalytic activity compared with their reference catalysts.
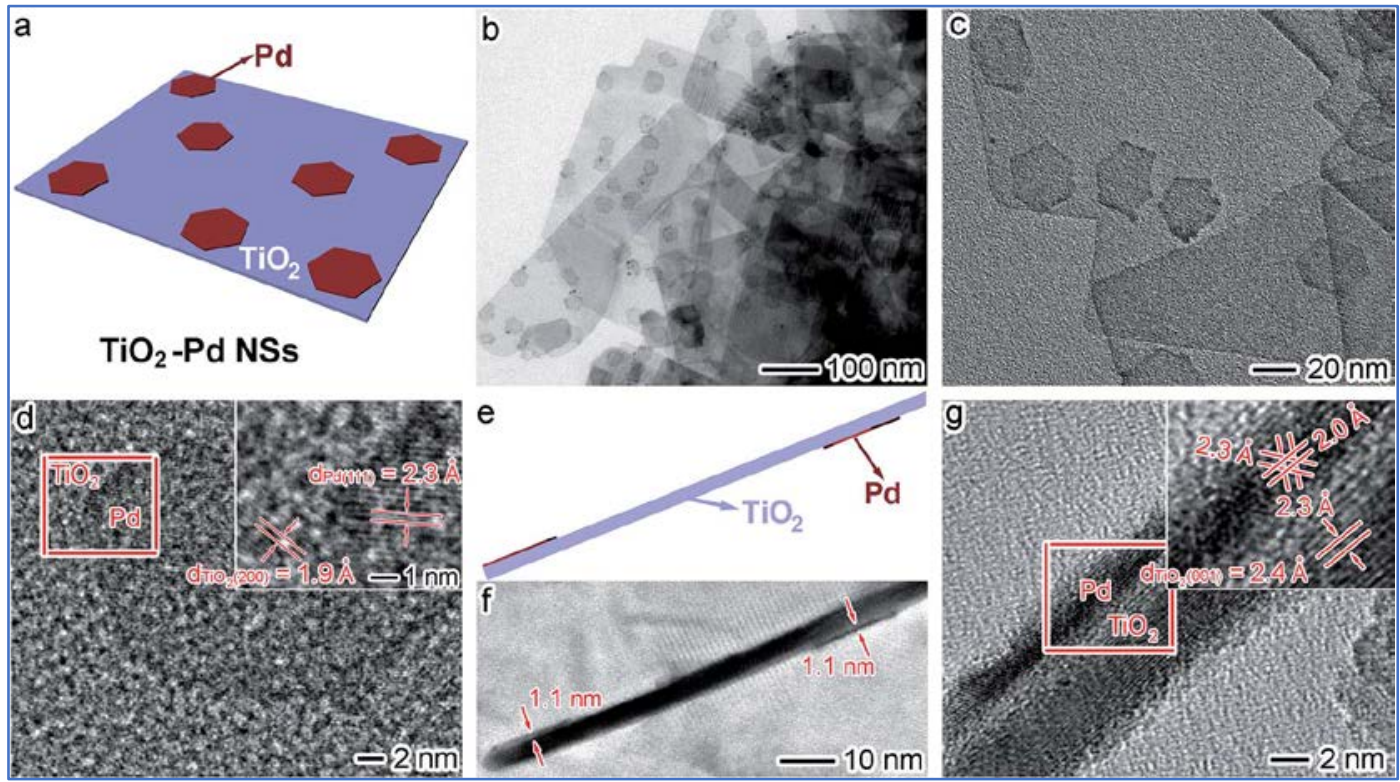

Fig. 17 (a) Schematic illustration, (b, c) TEM, and (d) HRTEM images of $\mathrm{TiO}_{2}-\mathrm{Pd}$ NSs; (e) schematic illustration, (f) TEM, and (g) HRTEM images of $\mathrm{TiO}_{2}-\mathrm{Pd}$ NSs with a standing-up $\mathrm{TiO}_{2}$ nanosheet. Reproduced with permission from Ref ${ }^{81}$

\subsection{Non-metallic plasmonic photocatalysts}

Recent years have seen some non-metallic plamonic semiconductor photocatalysts such as $\mathrm{Cu}_{2} \mathrm{~S}, \mathrm{WO}_{3}$, $\mathrm{MoO}_{3}, \quad \mathrm{Bi}_{2} \mathrm{Se}_{3}$ and $\mathrm{In}_{2} \mathrm{O}_{3}{ }^{84}$ This development significantly expands the range of plasmonic nanomaterials and could possibly put down the cost of metallic plamonic catalysts.

$\mathrm{Cu}_{2-\mathrm{x}} \mathrm{S}(\mathrm{x}=1,0.2,0.03)$ nanocrystals (also known as a kind semiconductor) synthesised with three different chemical methods (sonoelectrochemical, hydrothermal, and solventless thermolysis methods) were shown to have different crystilinity, morphology, and optical and structural properties, thereby exhibiting different plasmonic properties. The optical properties of these $\mathrm{Cu}_{2-\mathrm{x}} \mathrm{S}$ nanocrystals characterised by UV/Vis and NIR presented that $\mathrm{Cu}_{2-\mathrm{x}} \mathrm{S}$ nanocrystals show a blue shift in the band gap absorption compared with bulk $\mathrm{Cu}_{2-x} \mathrm{~S}$ $\left(\mathrm{Cu}_{1.97} \mathrm{~S}\right)$. Moreover, the spectra of these $\mathrm{Cu}_{2-\mathrm{x}} \mathrm{S}$ nanocrystals indicate direct band gap character based on their oscillator strengths, and the NIR spectra show a carrier concentration dependent plasmonic absorption. ${ }^{85}$ Other studies demonstrate that the wavelengths of these 
LSPR modes can be modulated by independently varying the aspect ratio of the disk and the overall carrier density of $\mathrm{Cu}_{2-\mathrm{x}} \mathrm{S}$ by performing thermolysis of a $\mathrm{Cu}-$ alkanethiolate precursor under a $\mathrm{N}_{2}$ gas environment and by thermal oxidation, respectively, as shown in Fig. 18. ${ }^{14}$

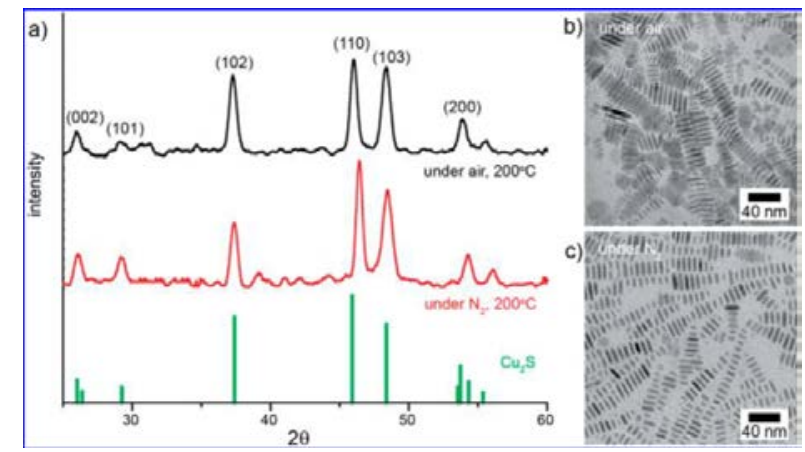

Fig. 18 XRD spectra and TEM images of nanodisks synthesised under air and $N_{2}$. (a) XRD spectra show that both nanocrystal powders possess a crystal structure closely resembling the hexagonal lattice of stoichiometric chalcocite $\left(\mathrm{Cu}_{2} \mathrm{~S}\right)$. (b) The morphology obtained for both samples are disk-shaped nanocrystals, seen here in stacked pancake-like structures that occur during evaporative assembly at an airwater interface. Reproduced with permission from Ref. ${ }^{\mathbf{1 4}}$
Transition-metal oxide nanocrystals are interesting candidates for localised surface plasmon resonance hosts because they exhibit fascinating properties arising from the unique character of their outer-d valence electrons.

$\mathrm{WO}_{3-\delta}\left(\mathrm{WO}_{2.83}\right.$ typical) nanoparticles are known to have intense visible and near-IR absorption. Manthiram and co-workers' study demonstrates that metallic phases of $\mathrm{WO}_{3-\delta}$ nanoparticles exhibit a strong and tunable localised surface plasmon resonance, which opens up the possibility of rationally designing plasmonic tungsten oxide nanoparticles for light harvesting, bioimaging, and sensing. ${ }^{15} \mathrm{Kim}$ and coworkers' study reveals that doped $\mathrm{WO}_{3}$ nanocrystals by $\mathrm{Cs}$ exhibit strong aspect ratiodependent LSPR absorption peaks that can only be explained via a cooperative influence of crystalline and shape anisotropies as shown in Fig. 19. This finding highlights the limitations of conventional treatments of LSPR that assume isotropic dielectric constants and attribute multimodal peaks uniquely to shape anisotropy effects and extends our ability to rationally tune LSPR line shape and near-field enhancement via synthetic control of shape and crystalline anisotropies of semiconductor nanocrystals. ${ }^{86}$
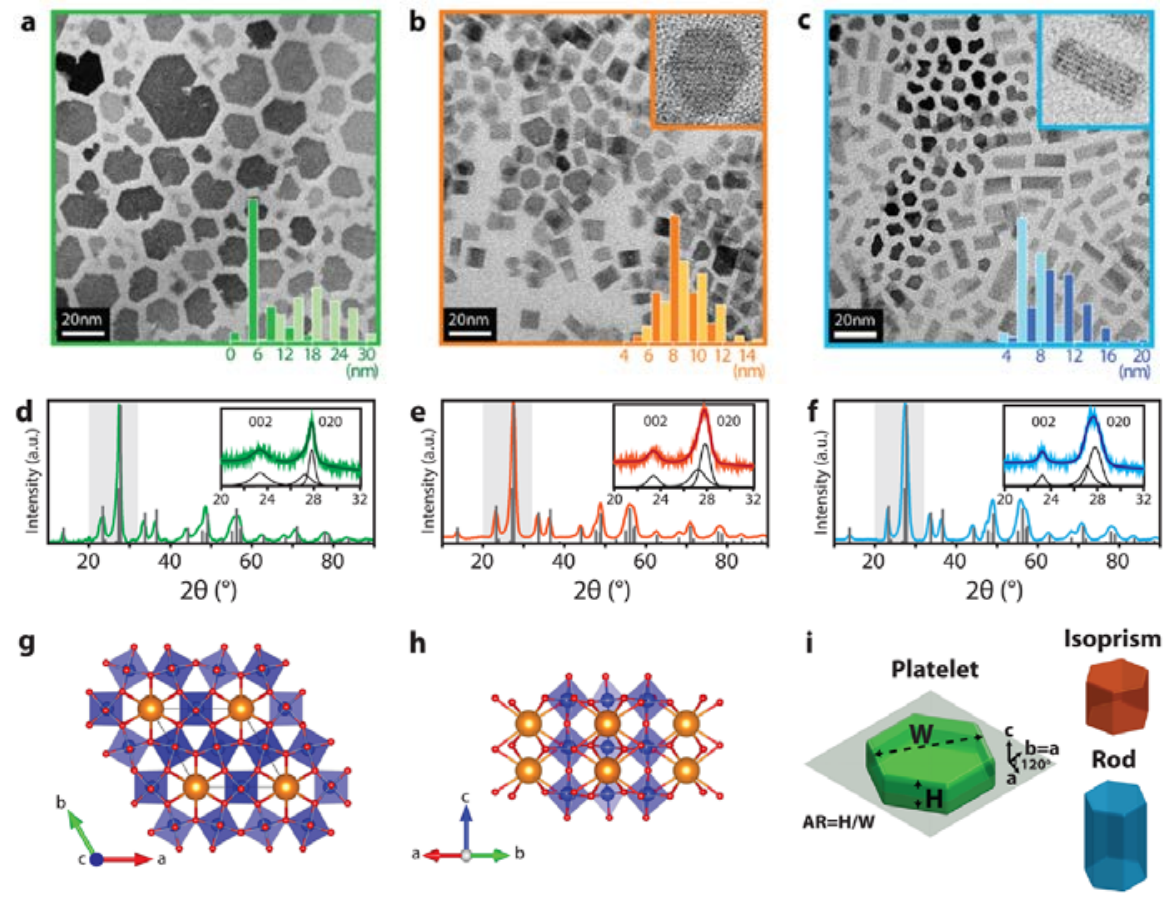

Fig. 19 Hexagonal cesium-doped tungsten oxide (h-Cs: $\mathrm{WO}_{3}$ ) nanocrystals with different aspect ratios. (a-c) TEM images of h-Cs:WO 3 nanocrystals in the shape of (a) platelets, (b) iso-prisms, and (c) rods. The bottom right insets in a-c are size distribution histograms for the average height (dark color bars) and width (light color bars) of nanocrystals. (d-f) XRD patterns for the h-Cs:WO 3 nanocrystal samples corresponding to $\mathrm{a}-\mathrm{c}$. The insets in $\mathrm{d}-\mathrm{f}$ are high-resolution XRD patterns of the gray regions, containing the (002) and (020) peaks that exhibit size-dependent broadening corresponding, respectively, to the height and width of nanocrystals. (g-h) Illustration of the h-Cs:WO 3 lattice structure projection on the (g) basal plane and (h) prismatic plane: Cs (gold), W (blue), and O (red). (i) Schematic illustration of nanocrystal shape corresponding to a-c showing the conventions used. Reproduced with permission from Ref. ${ }^{\mathbf{8 6}}$ 
Besides $\mathrm{WO}_{3}, \mathrm{MoO}_{3-\mathrm{x}}$ nanosheets also display intense absorption in a wide range attributed to the localised surface plasmon resonances (Fig. 20). The absorption can be tuned from the visible to the near-infrared region. It is demonstrated that such plasmonic semiconductor nanostructures could be used as highly efficient catalysts that dramatically enhance the hydrogen-generation activity of ammonia borane under visible light irradiation. $^{13}$

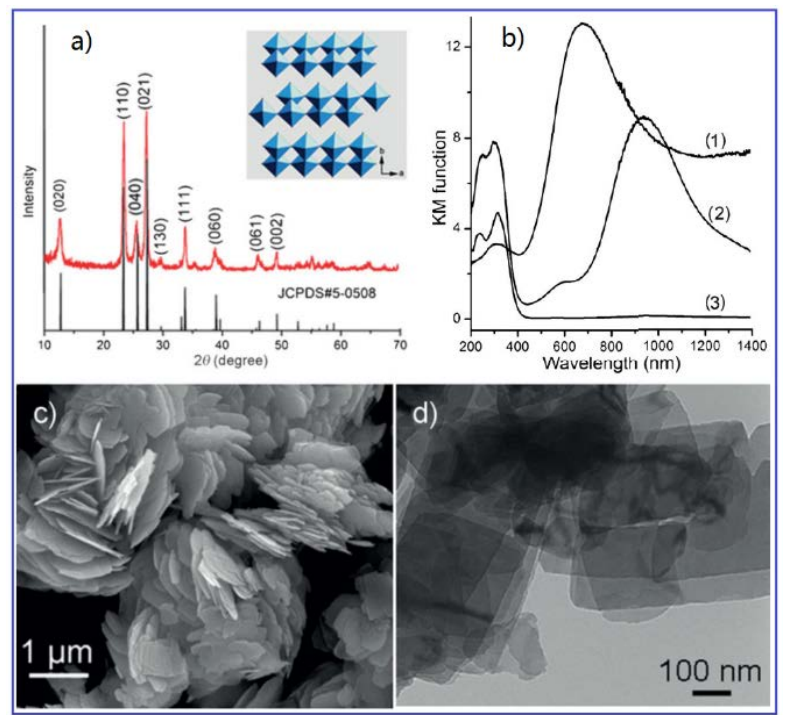

Fig. 20 (a). XRD pattern of $\mathrm{MoO}_{3-x}$ and (inset) crystal structure of the orthorhombic $\mathrm{MoO}_{3}$ (b). UV/Vis-NIR diffuse reflectance spectra of the $\mathrm{MoO}_{3-x}$ samples prepared at $160^{\circ} \mathrm{C}$ (1) and $140^{\circ} \mathrm{C}$ (2) for $12 \mathrm{~h}$, and commercial $\mathrm{MoO}_{3}$ (3). SEM (c) and TEM (d) images of the $\mathrm{MoO}_{3-x}$ products. Reproduced with permission from Ref. ${ }^{\mathbf{1 3}}$

$\mathrm{Bi}$ nanoparticles and $\mathrm{Bi}_{2} \mathrm{Se}_{3}$ are also reported to be plasmonic photcatalysts. Dong and co-workers' study shows that the highly enhanced activity was attributed to the cooperative contribution of the localised surface plasmon resonance, the efficient separation of electronhole pairs, and the prolonged lifetime of charge carriers by the $\mathrm{Bi}$ nanoparticles. ${ }^{87}$ The behavior of $\mathrm{Bi}$ nanoparticles as a co-catalyst for boosting photocatalytic activity is similar to that of noble metals in photocatalysis. It is interesting that the $\mathrm{Bi} / \mathrm{BOC}(\mathrm{BOC}=$ $(\mathrm{BiO})_{2} \mathrm{CO}_{3}$ ) sample displayed a high photochemical stability under repeated irradiation (Fig. 21). In Dong and co-workers' another study, they employ Bi metal to activate the amorphous semiconductor of bismuth oxide to enhance the photocatalytic removal of NO in air. ${ }^{\mathbf{8 8}}$ These studies demonstrated the feasibility of utilising low-cost Bi nanoparticles as a substitute for noble metals to enhance visible light photocatalysis. ${ }^{89}$ Moreover,
$\mathrm{Bi}_{2} \mathrm{Se}_{3}$ topological insulator hierarchical nano-flowers, which are consisted of a large number of $\mathrm{Bi}_{2} \mathrm{Se}_{3}$ nanocrystals also show the LSPR effect. The existence of LSPR can be demonstrated by surface enhanced Raman scattering and absorbance spectra ranging from ultraviolet to near-infrared. ${ }^{90}$
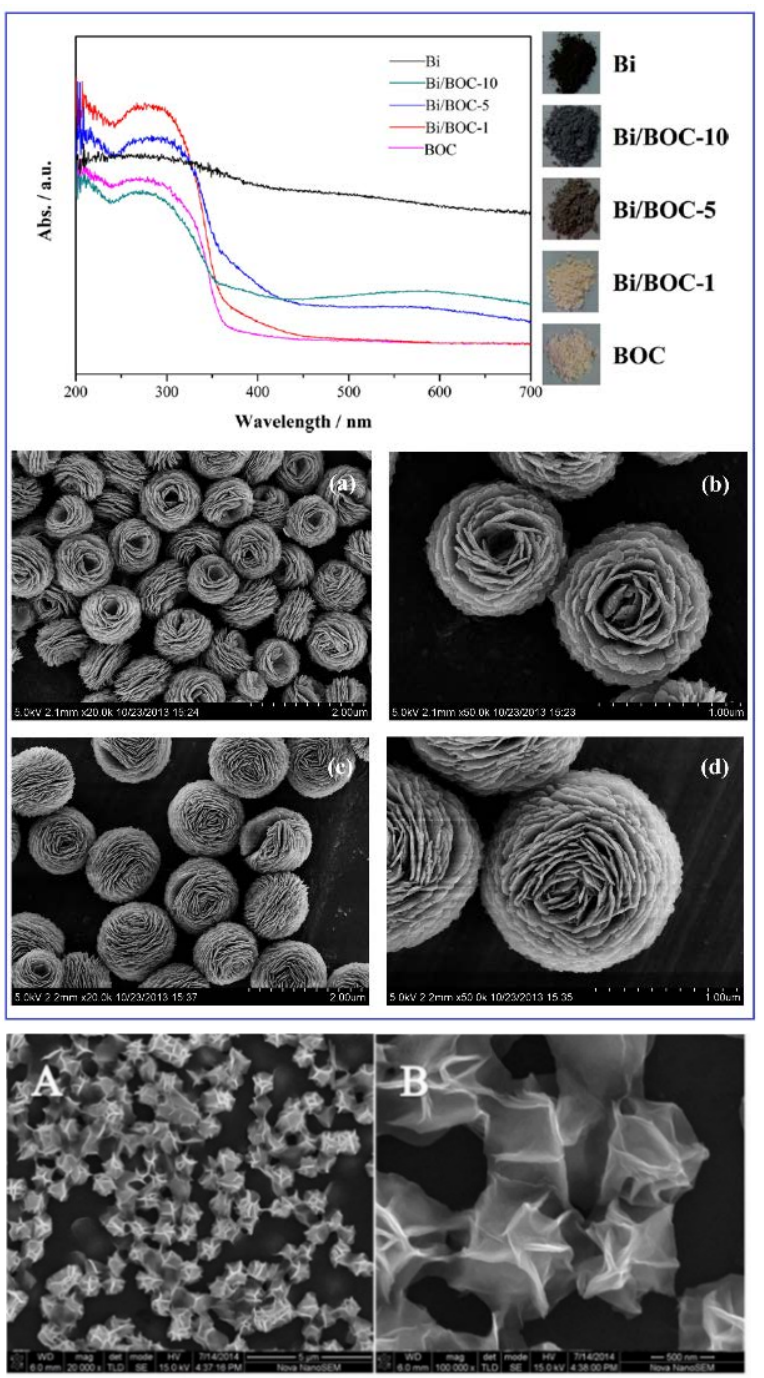

Fig. 21 (Up) UV-vis DRS spectra of $\mathrm{BOC}, \mathrm{Bi} / \mathrm{BOC}$, and $\mathrm{Bi}$ samples. The insets give photos of sample color. The mass ratios of thiourea to $(\mathrm{BiO})_{2} \mathrm{CO}_{3}$ were controlled at $1 \%, 5 \%$, and $10 \%$, and the resulting samples were labelled as Bi/ BOC-1, Bi/BOC-5, and Bi/BOC-10, respectively. Reproduced with permission from Ref. ${ }^{87}$ (Down, A and B) SEM images of BOC $(a, b)$ and Bi/BOC-1 (c, d). (Right) Morphology and structure of $\mathrm{Bi}_{2} \mathrm{Se}_{3}$ nanomaterials. SEM images of hierarchical $\mathrm{Bi}_{2} \mathrm{Se}_{3} \mathrm{NF}$ samples (A,B). Reproduced with permission from Ref. ${ }^{90}$

\section{Selectivity regulation in chemical synthesis}

Though numerous studies focused on the enhancement effect of plasmonic nanostructures, few discuss in particular the methods to selectively enhance some certain reactants and to regulate the catalytic selectivity. 
Nevertheless, analysing the reported results in plasmonmediated photocatalysis, we realise that the enhancement effect lies not only in the light absorption efficiency of incident light to boost the photocatalytic activity, but also in the selectivity of targeted product. Herein we summarise the influential factors into "internal" and "external" ones, and this categorisation may be arbitrary but it is convenient to differentiate the contributions of photocatalytic nanomaterials and manipulation of reaction conditions. To enlarge this part, internal factors are from the perspective of intrinsic properties of photocatalysts, including such as the utilisation of plasmoics, supports, promoters or co-catalysts; external factors are from the perspective of change in reaction environment, including such as choice of solvent, reactants and control of concentration, temperature, pressure, time and even the $\mathrm{pH}$ values. As to the photocatalytic applications, plasmonic catalysts have been dominantly investigated in $\mathrm{H}_{2}$ evolution, $\mathrm{CO}_{2}$ reduction, $\mathrm{CO}$ oxidation, pollutants degradation and chemical synthesis. Here we principally concentrate on the chemical synthesis in photocatalysis and its mechanism on regulating catalytic selectivity.

\subsection{Internal factors}

\subsubsection{Metal type, content, and composition}

The above-summarised metals that can show plasmonic effect are mainly $\mathrm{Au}, \mathrm{Ag}, \mathrm{Cu}, \mathrm{Pt}, \mathrm{Rh}$ and $\mathrm{Pd}$. A direct approach to regulate the selectivity of the target product is to use certain metallic active centres because they intrinsically possess different catalytic properties even though with the same light source irradiation. For instance, Zheng and co-workers investigated the visible light-induced catalytic oxidation of benzene in water with $\mathrm{Au}, \mathrm{Pt}$, and $\mathrm{Ag} @ \mathrm{TiO}_{2}$-microspheres (1 wt\%) in the presence of aqueous phenol. ${ }^{91}$ They found $\mathrm{Au} / \mathrm{TiO}_{2}$ performed best to produce phenol (Fig. 22a) and that further increasing the $\mathrm{Au}$ content from $2 \%$ to $3 \%$, the selectivity decreased from $91 \%$ to $78 \%$, indicating the existence of a optimal loading of Au (Fig. 22b). This study demonstrates that metal category is the inherent determinant of catalytic performances and absorption range of light irradiation (Fig. 22c); and is influenced by content of a metal which correspondingly changes the light absorption capacity (Fig. 22d).
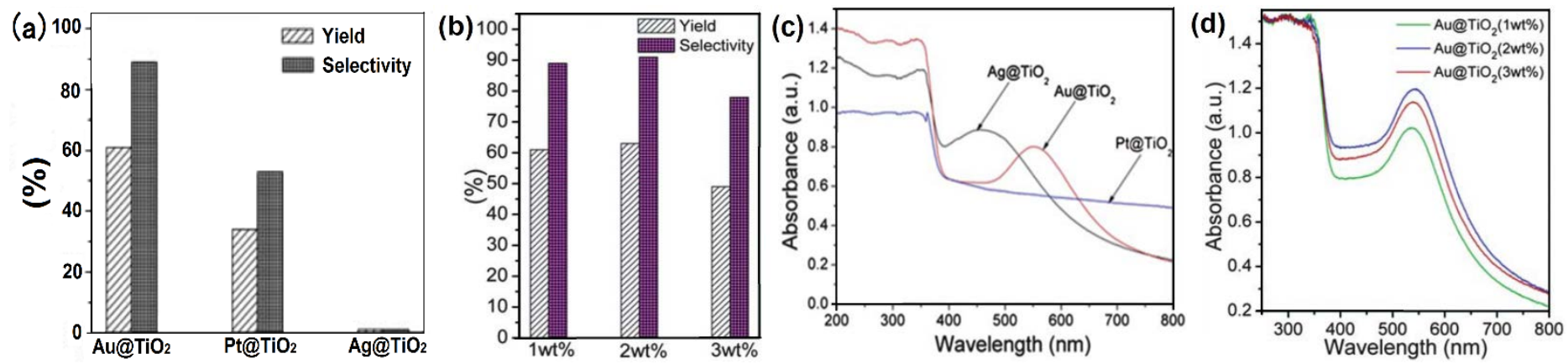

Fig. 22 (a) Visible-light-induced catalytic oxidation of benzene and variation in the yield and selectivity of phenol formation over different photocatalysts. (b) variation in the yield and selectivity over Au@TiO 2 -microsphere composites with 1-3 wt \% of Au. (c) UV/Vis diffusereflectance spectra of noble-metal@TiO 2 -microspheres with loading of 1 wt \% noble metal, and (d) UV/Vis diffuse-reflectance spectra of $\mathrm{Au} @ \mathrm{TiO}_{2}$-microsphere composites. Reproduced with permission from Ref. ${ }^{\mathbf{1 1}}$

The oxidation sate of the metal (can be regarded as the change in composition) affects the electronic properties, and thus substantially determines the interaction between the metal nanostructures and the incident light. Marimuthu and co-workers' study demonstrate that the oxidation of functioning $\mathrm{Cu},{ }^{92}$ which has restricted its applicability as a catalyst for commercially important epoxidation of propylene to form propylene oxide $\left(\mathrm{C}_{3} \mathrm{H}_{6}\right.$ $+1 / 2 \mathrm{O}_{2} \rightarrow \mathrm{C}_{3} \mathrm{H}_{6} \mathrm{O}$ ), can be tuned by light irradiation and that the steady-state selectivity in propylene epoxidation on $\mathrm{Cu}$ NPs increases sharply from $\sim 20$ to $\sim 50 \%$ (Fig. 23a) when the catalyst is illuminated with visible light. It is observed that the selectivity increase is accompanied by light-induced reduction of the surface $\mathrm{Cu}$ atoms from $\mathrm{Cu}$ oxide (light off) to $\mathrm{Cu}$ metal (light on) (Fig. 23b), which is brought about by photo-excitation of the LSPR of $\mathrm{Cu}$ to weaken the $\mathrm{Cu}-\mathrm{O}$ bonds, reducing $\mathrm{Cu}_{2} \mathrm{O}$. They also find that at a critical light intensity threshold, the change in the product selectivity and $\mathrm{Cu}$ oxidation state are observed within less than 2 min under the detection limit of then experimental setup, and the result are shown in the following Fig. 23c. 
(a)

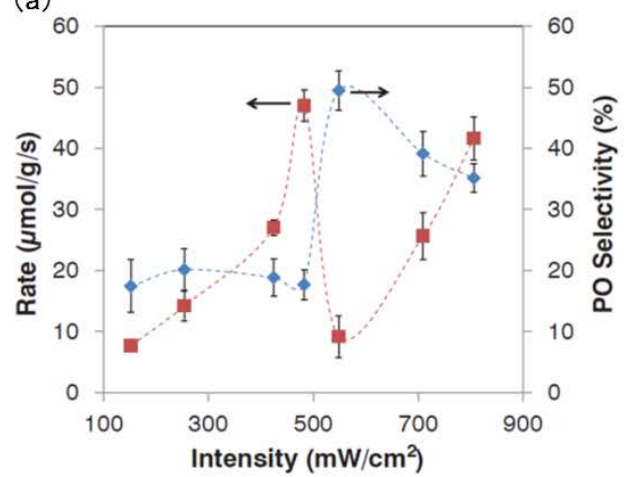

(b)

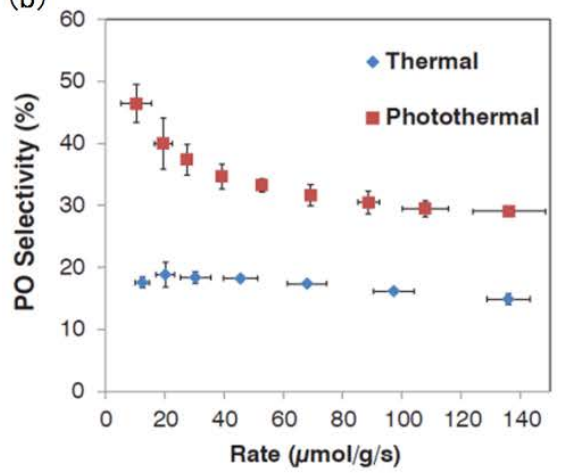

(c)

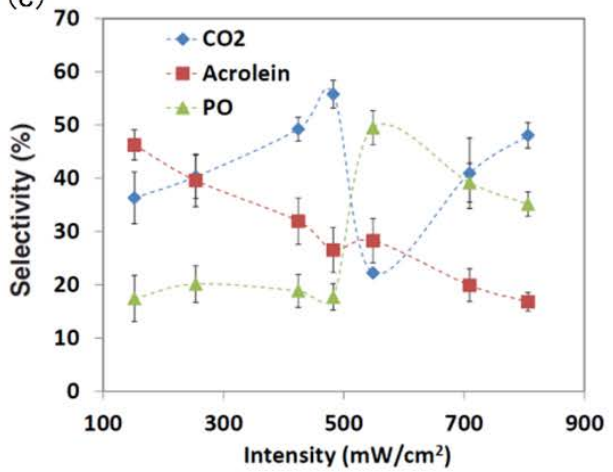

Fig. 23 (a) Rate of propylene consumption (left axis, red squares) and the selectivity to PO (propylene oxide, right axis, blue diamonds) under photothermal conditions (light on) at $473 \mathrm{~K}$ as a function of light intensity. The rate and selectivity data shown in (a) represent the average values of the data obtained from five independent experiments, and the error bars represent SD (standard deviation). (b) Selectivity to PO for thermal (light off) and photothermal (light on) processes as a function of the reaction rate. The light intensity used for the photothermal studies was $550 \mathrm{~mW} / \mathrm{cm}^{2}$. The reaction rate and selectivity data shown in (b) represent the average values of the data obtained from three independent experiments, and the error bars represent SD. (c) Selectivity to $\mathrm{PO}$, acrolein and $\mathrm{CO}_{2}$ under photothermal conditions at $473 \mathrm{~K}$ as a function of light intensity. The selectivity data shown in the figure represent the average values of the data obtained from five independent experiments and the error bars represent the standard deviations. Reproduced with permission from Ref. ${ }^{92}$

The elemental ratio of alloy or bimetallic plasmonic photocatalysts is expected to show different catalytic activities or selectivity with various compositions under light irradiation. A case in point is Xiao and co-workers' study on $\mathrm{Au}-\mathrm{Cu}$ alloy nanopartiles for the selective reduction of nitroaromatics to anilines (Fig. 24). ${ }^{93}$ The reasons for the high efficiency of the photocatalytic reduction under these comparatively benign conditions are as the following. The nitro group is transformed to an amino group directly rather than in a stepwise manner via a series of intermediates as described. The interaction between the nitro group and copper atoms is stronger than that between the nitro group and gold atoms, thereby immobilising the reactant. This effect facilitates direct reduction of the nitro group to an amino-group and impedes the coupling reaction between two intermediate molecules. The change in reaction pathway and mild reaction conditions are the essential reasons for the high chemoselectivity for the anilines. The authors also find that the catalytic reaction rate can be further optimised by a slight increase in the reaction temperature, whereas the high chemoselectivity for reduction of the nitro groups is maintained. From the same group, Liu and co-workers report that supported Ag-Cu alloy nanoparticles are able to selectively transform nitrobenzene to azoxybenzene by visible light irradiation under green mild reaction conditions. And the photocatalytic performance was affected by the ratio of $\mathrm{Ag}-\mathrm{Cu}$, with an optimised Ag-Cu molar ratio of 4-1.56
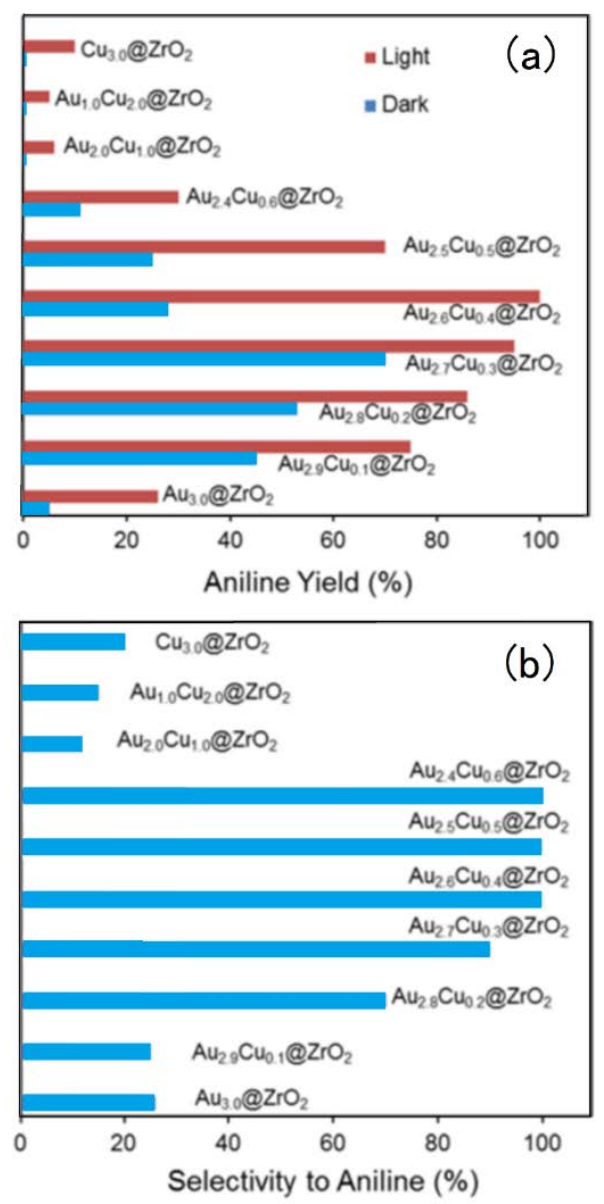

Fig. 24 Photocatalytic performance for the reduction of nitrobenzene: (a) Au-Cu alloy NPs @ $\mathrm{ZrO}_{2}$ catalysts with varied composition. (b) The dependence of the product selectivity to aniline on the Au-Cu alloy NPs @ $\mathrm{ZrO}_{2}$ catalysts with varied $\mathrm{Au} / \mathrm{Cu}$ composition under visible-light irradiation. Reproduced with permission from Ref. ${ }^{93}$ 
These studies suggest that the product selectivity may be engineered simply by tailoring the alloy nanoparticles of the photocatalysts. This approach to tuning alloy composition and structures represents a promising new direction in the area of photocatalytic chemical transformations.

\subsubsection{Catalyst supports and hot electrons}

Supporting materials are important to tailor the catalytic properties of catalytically active sites, the key mechanisms behind support-induced or even supportdependent phenomena in the catalytic properties of metal nanoparticles include support-induced changes in morphology, stability, electronic structure, and chemical oxidation state, and changes in the supports themselves. Therefore, the strong metal-support interaction (SMSI) between metal nanoparticles and supports and the synergistic effect of metal sites and supports on catalytic performances are rather popular in catalyst systems. Regarding the SMSI and supports-induced interaction, there are well-documented literature, ${ }^{94,}{ }^{95},{ }^{96}$ here we highlight their applications in plasmonic photocatalytic catalysis.

In plasmonic photocatalysts, many researchers examine the support effect on catalytic performances. Ke and co-workers' study show that Au NPs supported on different supports show different catalytic performances (selectivity) as to the reduction of styrene oxide to styrene, shown below. ${ }^{97},{ }^{98}$ The TEM images of these catalysts are shown in Fig. 25. The light absorption is important to the photocatalytic performance, but the catalytic activity also depends on other factors, particularly the interfacial behaviours occurring between the Au NPs and supports as the photocatalytic reactions take place on the Au NP surface with the aid of supports. Some researchers propose electron transitions between $\mathrm{Au}$ NPs and the support $\left(\mathrm{TiO}_{2}\right)$, which is not perfect to clarify the functions of supports, particularly in the photocatalytic process. $\mathrm{Au} / \mathrm{CeO}_{2}$ has a stronger interaction between $\mathrm{Au} \mathrm{NPs}$ and $\mathrm{CeO}_{2}$ and has a stable structure with $\mathrm{Au}$ NPs incorporated into $\mathrm{CeO}_{2}$, which has been identified previously. Thus in a reactive system the aggregation of Au NPs can be avoided and intensive light absorption is maintained. Au NPs were also loaded on $\mathrm{TiO}_{2}$ and $\mathrm{ZrO}_{2}$ and we found that for reduction of styrene oxide the selectivity to the product styrene is moderately lower than that of the $\mathrm{Au} / \mathrm{CeO}_{2}$ (Table 1).
Nevertheless, all the supports themselves show trivial activities in these photocatalytic reductions. It appears that the support materials have a limited impact on the conversion of photocatalytic reductions.

Table 1 Influence of supports on reduction of styrene oxides over supported Au NPs.

\begin{tabular}{|l|l|l|l|l|}
\hline \multirow{2}{*}{ Catalysts } & \multicolumn{3}{l|}{ Visible light } & No light \\
\cline { 2 - 5 } & Conv. (\%) & Sele. (\%) & Conv. (\%) & Sele. (\%) \\
\hline $\mathrm{Au} / \mathrm{CeO}_{2}$ & 19.7 & 88 & 4.4 & 72 \\
\hline $\mathrm{Au} / \mathrm{ZrO}_{2}$ & 17.4 & 72 & 7.8 & 75 \\
\hline $\mathrm{Au} / \mathrm{TiO}_{2}$ & 22.5 & 73 & 7.8 & 75 \\
\hline $\mathrm{Au} / \mathrm{Al}_{2} \mathrm{O}_{3}$ & 23.9 & 60 & 5.8 & 51 \\
\hline $\mathrm{Au} / \mathrm{Y}$ & 4.5 & 62 & 1.6 & 55 \\
\hline
\end{tabular}

Reaction time. 16h. Reproduced with permission from Ref. ${ }^{98}$

Influence of support physiochemical properties was also examined in the oxidative esterification in the absence of added base. ${ }^{68}$ Results of specific surface areas of the photocatalysts (derived from nitrogen sorption data) and the surface acidity of the samples (measured by $\mathrm{NH}_{3}$ temperature-programmed desorption, $\mathrm{NH}_{3}$-TPD) indicate that specific surface area is not the decisive factor on the catalytic performance, as the optimal photocatalyst has a relatively small specific surface area. Basic sites on the support surface alone cannot simply be the dominate factor enhancing the catalyst performance, since MgO and HT have basic surface sites but AuPd@MgO and Au-Pd@HT exhibit low and moderate activity, respectively. Therefore, a moderate population of basic/acidic sites on the supports is necessary for the catalysis, and the basic surface sites from $\mathrm{PO}_{4}{ }^{3-}$ are superior to other basic sites for the catalytic performance. The unique surface character of the Au-Pd@HT-PO ${ }_{4}^{3-}$ catalyst is essential for facilitating the base-free direct oxidative esterification of aliphatic alcohols. The content of $\mathrm{PO}_{4}{ }^{3-}$ in the HT support also affects the catalytic activity (Table 2). According to the results of EDX analysis, when the phosphorus content is $0.2 \mathrm{wt} \%$ of the catalyst, the catalyst exhibits the best performance; further increasing the amount of $\mathrm{PO}_{4}{ }^{3-}$ can suppress the conversion rate and ester selectivity. Thus, a small amount of phosphate exchanged into the HT support can provide necessary basic/acidic sites for the catalysed reactions and thus avoid the need to add base for efficient conversion. 
Table 2 Activity test of different supports for base-free oxidative esterification of 1-octanol ${ }^{\mathrm{a}}$

\begin{tabular}{|c|c|c|c|c|c|c|c|}
\hline & & & $\begin{array}{c}\text { Photocatalyst, hv } \\
1 \text { atm } \mathrm{O}_{2}, 55^{\circ} \mathrm{C}, 24 \mathrm{~h}\end{array}$ & & & & \\
\hline Entry & Catalysts & $\begin{array}{l}\text { BET Surface } \\
\text { area }\left(\mathrm{m}^{2} / \mathrm{g}\right)^{\mathrm{b}}\end{array}$ & $\begin{array}{l}\text { Acid density } \\
(\mathrm{mmol} / \mathrm{g})^{\mathrm{c}}\end{array}$ & Incident light & Conv. (\%) & $\begin{array}{l}\text { Ester sele. } \\
(\%)\end{array}$ & $\begin{array}{l}\text { Ester yield } \\
(\%)\end{array}$ \\
\hline \multirow[t]{2}{*}{1} & \multirow[t]{2}{*}{$\mathrm{Au}-\mathrm{Pd} @ \mathrm{HT}-\mathrm{PO}_{4}{ }^{3-}$} & \multirow[t]{2}{*}{13} & \multirow[t]{2}{*}{0.91} & Visible & 94 & 76 & 72 \\
\hline & & & & dark & 62 & 42 & 26 \\
\hline \multirow[t]{2}{*}{2} & \multirow[t]{2}{*}{ Au-Pd@HT } & \multirow[t]{2}{*}{59} & \multirow[t]{2}{*}{1.00} & Visible & 48 & 54 & 26 \\
\hline & & & & dark & 45 & 3 & 2 \\
\hline \multirow[t]{2}{*}{3} & \multirow{2}{*}{$\mathrm{Au}-\mathrm{Pd} @ \mathrm{Al}_{2} \mathrm{O}_{3}$} & \multirow[t]{2}{*}{201} & \multirow[t]{2}{*}{1.07} & Visible & 51 & 92 & 47 \\
\hline & & & & dark & 33 & 5 & 2 \\
\hline \multirow[t]{2}{*}{4} & \multirow[t]{2}{*}{ Au-Pd@MgO } & \multirow[t]{2}{*}{3} & \multirow[t]{2}{*}{0.03} & Visible & 20 & 34 & 7 \\
\hline & & & & dark & 3 & 0 & 0 \\
\hline \multirow[t]{2}{*}{5} & \multirow[t]{2}{*}{$\mathrm{Au}-\mathrm{Pd} @ \mathrm{ZrO}_{2}$} & \multirow[t]{2}{*}{20} & \multirow[t]{2}{*}{0.20} & Visible & 38 & 47 & 19 \\
\hline & & & & dark & 33 & 36 & 12 \\
\hline
\end{tabular}

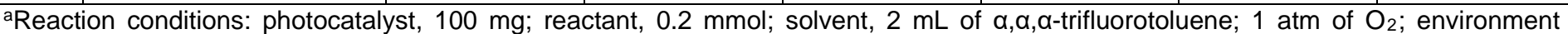
temperature; $55^{\circ} \mathrm{C}$; reaction time, $24 \mathrm{~h}$; and light intensity, $0.5 \mathrm{~W} / \mathrm{cm}^{2}$. The conversions and selectivity were calculated from the product formed and the reactantconverted, as measured by GC. bDetermined by adsorption-desorption of nitrogen. ${ }^{\mathrm{C}}$ Determined by $\mathrm{NH}_{3}-\mathrm{TPD}$. Reproduced with permission from Ref. ${ }^{68}$

The aforementioned studies on support effect demonstrates its influence on the overall catalytic performances, both activity and selectivity or yield. Nevertheless, there still lacks detailed mechanism on the way to regulate the product selectivity of plasmonic photocatalsyts under visible light irradiation, as the support effect is quite popularly seen in conventional catalysis driven by heat. ${ }^{\mathbf{9 9}, \mathbf{1 0 0}, \mathbf{1 0 1}}$ Therefore, it would be intriguing if investigation is directed to the plasmonic effect on supporting materials and thereafter the change in catalytic performances. To this end, Zhang and coworkers employed zeolites as supports and investigate the contribution of plasmonic effect on the external cations, including $\mathrm{H}^{+}, \mathrm{Na}^{+}, \mathrm{Ca}^{2+}$ and $\mathrm{La}^{3+}$, and thus on the catalytic performances of zeolites under visible light irradiation. ${ }^{35}$ It is demonstrated that the polarised electric fields can be further intensified by the electric near-field enhancement of Au NPs, which results from the localised surface plasmon resonance (LSPR) upon visible light irradiation (as illustrated in Fig. 25), and that the intensified polarised electric fields played a critical role in stretching the $\mathrm{C}=\mathrm{O}$ bond of the reactants of benzaldehyde to enlarge their molecular polarities, thus allowing reactants to be activated more efficiently by catalytic centres so as to boost the reaction rates. Further studies using reactants with different function groups confirmed this finding. ${ }^{36}$ The limitation of these studies is that they have clarified the approach to design plasmonic catalysts with different, e.g. structures to regulate the catalytic selectivity; nonetheless, it highlights that reactants with different molecular polarities could be transformed to targeted products in a controlled manner, and this as an external factor will be discussed later on. ${ }^{\mathbf{1 0 2}}$

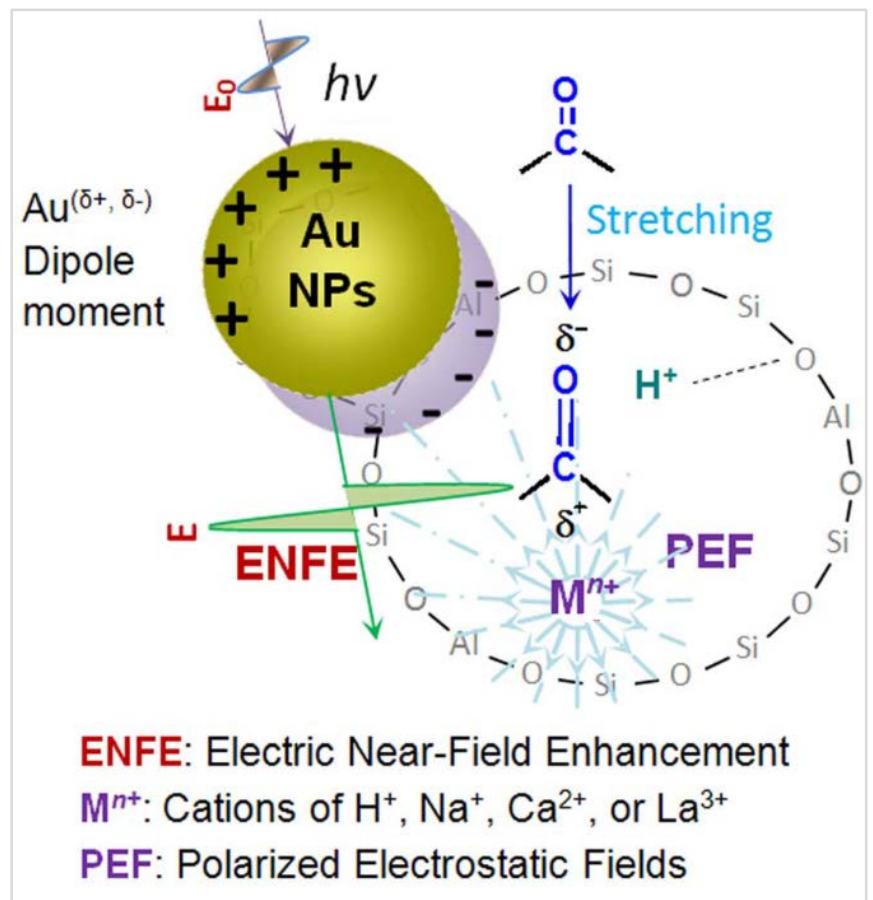

Fig. 25 The acetalisation on Au/MZSM-5 $\left(\mathrm{M}=\mathrm{H}^{+}, \mathrm{Na}^{+}, \mathrm{Ca}^{2+}\right.$, or $\mathrm{La}^{3+}$ ) under the irradiation of visible light. ENFE means the electric nearfield enhancement of Au NPs. PEF means the polarised electro-static fields of extra-framework cations in zeolites. Reproduced with permission from Ref. ${ }^{36}$

Besides supports, plasmonic metal nanoparticles themselves can efficiently convert the energy of visible photons into the energy of hot charge carriers within the nanoparticles. These energetic charge carriers can 
transfer to molecules or supports (including semiconductors, ${ }^{17,}{ }^{103}$ chemically attached to the plasmonic nanoparticles, where they can induce photochemical transformations. ${ }^{104},{ }^{105}$ Therefore, controlling photo-induced electrons has the potential to tune the catalytic activity or selectivity of plasmonic photocatalysts. The conversion efficiency of solar energy to chemical energy are critical, and for chemical synthesis, the selectivity towards a specific product is even more important, because it is strongly associated with chemical yield and cost to obtain pure target product. $^{\mathbf{1 6}}$

Mukherjee and co-workers' study demonstrates that plasmon-induced dissociation of $\mathrm{H}_{2}$ on Au NPs can happen at room temperature. ${ }^{\mathbf{1 0 6}}$ It is explained that the surface plasmons excited in the Au NP decay into hot electrons with energies between the vacuum level and the work function of the metal. In this transient state, hot electrons can transfer into a Feshbach resonance of an $\mathrm{H}_{2}$ molecule adsorbed on the Au NP surface, triggering dissociation, with the illustrated mechanism shown Fig. 26. In theory, by tuning the plasmon resonances of metal nanoparticles appropriately, it may be possible to populate specific electronic states of molecules adsorbed on the nanoparticle surface. This state-selective population of adsorbate resonances could be exploited to prepare reactants in specific states on nanoparticle surfaces, thus enabling an unprecedented, all-optical control of chemical reactions with a tailored product selectivity. This study has a great potential in hydrogenation reactions, particularly those with concomitant competing reactions. For instance, hydrogenation of glucose to sorbitol under heated aqueous conditions $\left(100-160^{\circ} \mathrm{C}\right)$ can inevitably introduce isomerisation of glucose to fructose, sorbitol to mannitol, and other polymerisation reactions that lead to formation of humins and deposition of carbonaceous species on catalysts. ${ }^{\mathbf{1 0 7}}$ The controlling step is $\mathrm{H}_{2}$ dissociation; hence, if the hydrogenation can undergo under ambient conditions using plamonic catalysts, the selectivity of sorbitol would be much higher.

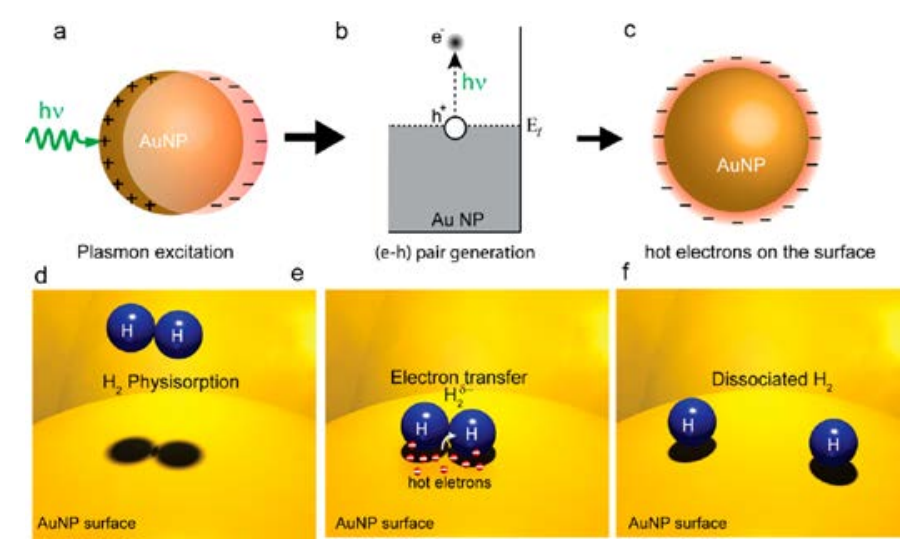

Fig. 26 Schematics of plasmon-induced hot electrons generation on Au NP and mechanistic representation of $\mathrm{H}_{2}$ dissociation on the Au NP surface. Reproduced with permission from Ref. ${ }^{106}$

\subsection{External factors}

Light source, light intensity or wavelength: In the study of plasmonic photocatalsis, the influence of light intensity or wavelength on boosting catalytic activity has been widely investigated, whereas the investigation into tuning catalytic selectivity is rare to see in literature. For types of light sources, such as simulated solar light, laser drop, light emitting diode (LED) and incandescent light, a study shows that the laser drop, LED, and microwave irradiation give rise to different catalytic results in the selective catalytic oxidation of sec-phenethyl and benzyl alcohol, using Au colloids as catalysts. ${ }^{108}$ It is found that the sec-phenethyl alcohol conversion was calculated to be $95 \%$ in 20 min when monochromatic $530 \mathrm{~nm}$ LEDs were used, showing an as good or better yield than the corresponding laser and microwave techniques (please refer to Table 3). This study demonstrates the versatility of this inexpensive arrangement of type of light source to achieve selective enhancement of alcohols.

Table 3 Summary of the Percent Conversions of secPhenethyl and Benzyl Alcohol Obtained Using Laser, LED, and Microwave Irradiation

\begin{tabular}{|l|l|l|}
\hline Method & $\begin{array}{l}\text { Sec-phenethyl } \\
\text { alcohol \% } \\
\text { Conversion }\end{array}$ & $\begin{array}{l}\text { Benzyl } \\
\text { alcohol \% } \\
\text { Conversion }\end{array}$ \\
\hline LD 100 shots/drops & 44.3 & 27.0 \\
\hline LD blank (100 shots/drops) & 2.8 & 1.0 \\
\hline LED 100s & 70.2 & 54.6 \\
\hline LED 20min & 95.2 & 66.3 \\
\hline LED blank (25 min) & 25.7 & 9.1 \\
\hline Microwave 1 min & 81.7 & 18.4 \\
\hline Microwave 10 min & 98.2 & 31.5 \\
\hline Microwave blank (10 min) & 2.8 & 2.8 \\
\hline
\end{tabular}

a Conversion to acetophenone. ${ }^{\mathrm{b}}$ Conversion to benzaldehyde. Reproduced with permission from Ref. ${ }^{108}$ 
Reactants, additives, and solvents: It is widely recognised that the physiochemical properties of a molecule, such as bond/molecular polarity, functional groups and adsorptivity, affect their reactivity and bonding conditions (e.g. formation of hydrogen bond with other molecules or catalyst surfaces). And the influence of these factors tends to be stronger in the presence of plasmonic nanostructures. ${ }^{109}$

An earlier study was performed on the selective enhancement by silver deposited on $\mathrm{TiO}_{2}$ for the oxidation of organic compounds (glucose, fructose, formic acid, citric acid, methanol, phenol, etc., as shown in Fig. 26). They found that the the enhancing effect for the saccharide group, increasing the glucose, fructose and sucrose mineralisation rates by factors of 7.2, 8.0 and 5.7, respectively. Similarly, the mineralisation of carboxylic acids, including oxalic acid and formic acid, were enhanced 3.7 and 2.9 times by the presence of silver deposits. Silver only marginally enhanced the mineralisation rates of acetic acid and dichloroacetic acid, and had no significant effect on the mineralisation of iso-butyric acid, as shown below. ${ }^{\mathbf{1 0 2}}$ They thus concluded that the fewer $\mathrm{C}-\mathrm{H}$ bonds and/or more $\mathrm{C}=\mathrm{O}$ and $\mathrm{C}-\mathrm{O}$ bonds a molecule possesses, the more probable the enhancement of mineralisation in the presence of silver.

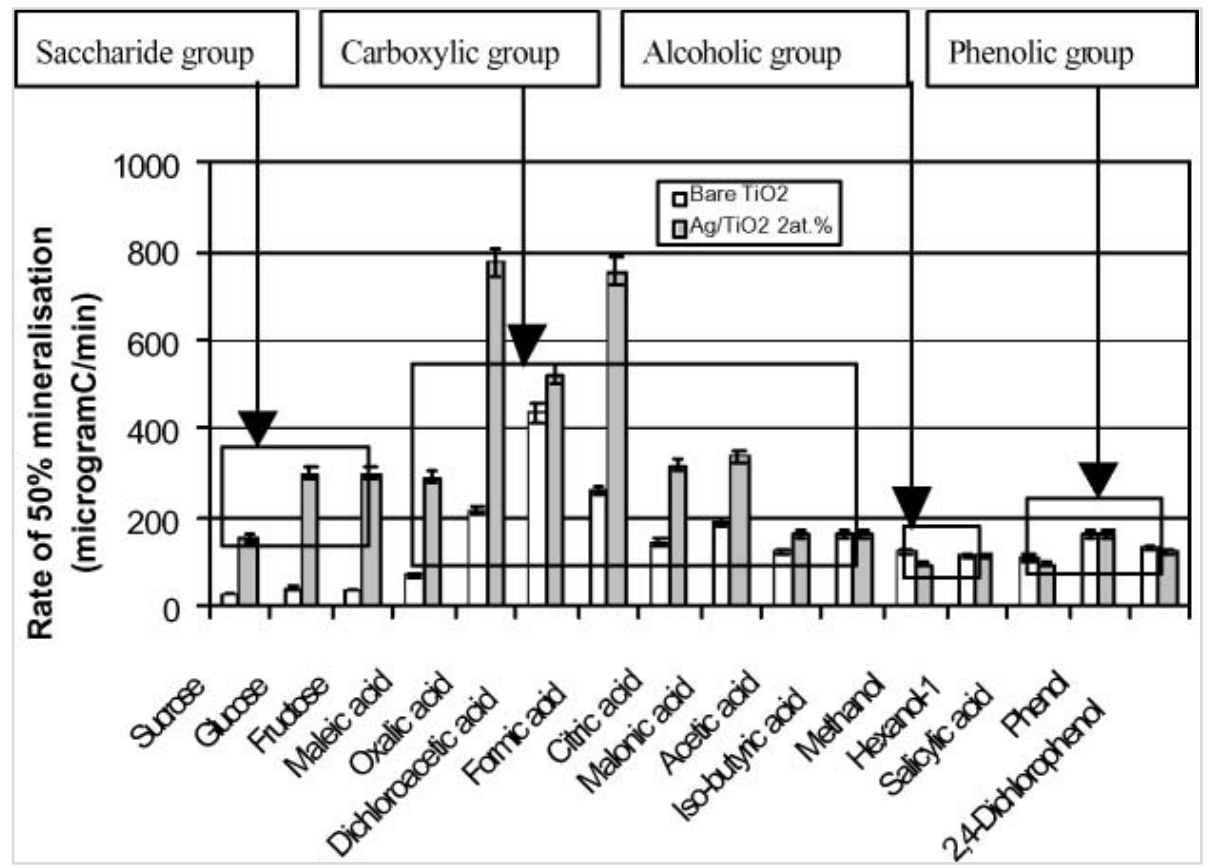

Fig. 27 Comparison of the mineralisation rates of 16 organic compounds by bare $\mathrm{TiO} 2$ and 2 atom\% $\mathrm{Ag} / \mathrm{TiO} 2$. Reproduced with permission from Ref. ${ }^{102}$

The above study attributes the intrinsic reason for the selective enhancement to the adsortivity of functional groups of these compounds and makes no discussion on the plasmonic effect of $\mathrm{Ag}$ and its contributions at that time. Zhu and co-workers studied the reduction of nitroaromatic compounds on supported Au NPs by visible and ultraviolet light and the following Table 4 lists the selectivity of products at the same conditions; however, not all the similar reactants game the same product selectivity (azo compound). ${ }^{\mathbf{1 1 0}}$ The reason for the difference in selectivity is not given, but the aforementioned two studies show that the choice of reactants is important to produce a certain product. That is, over a certain photocatalyst, the functional groups contained in a reactant would have their own way to interact with the plasmonic nanostructures under light irradiation, thereby giving different products. Similar findings are also reported in Zhao and co-workers' study, and it is on hydroamination of alkynes with amines on $\mathrm{Au} / \mathrm{TiO}_{2}-\mathrm{N}$ (under visible light). ${ }^{\mathbf{1 1 1}}$

Table 4 Reduction of nitroaromatic compounds in the presence of supported metal nanoparticles. ${ }^{\text {a }}$

\begin{tabular}{|l|l|l|l|l|}
\hline Reactant & Main product & $\begin{array}{l}\text { Conv. } \\
(\%)\end{array}$ & $\begin{array}{l}\text { Sele. } \\
(\%)\end{array}$ & $\begin{array}{l}\text { Photonic } \\
\text { efficiency } \\
(\%)\end{array}$ \\
\hline$\square-\mathrm{NO}_{2}$ & $100^{\mathrm{b}}$ & $>99$ & 6.9 \\
\hline & $100^{\mathrm{c}}$ & 95 & 7.3 \\
\hline
\end{tabular}




\begin{tabular}{|l|l|l|l|l|}
\hline $\mathrm{C}$ & $100^{\mathrm{d}}$ & 56 & 3.6 \\
\hline$-\mathrm{NO}_{2}$ & $58^{\mathrm{d}}$ & $>99$ & 2.1 \\
\hline $0 \mathrm{NO}_{2}$ & & & \\
\hline
\end{tabular}

${ }^{a}$ Reduction reaction was conducted in an argon atmosphere at 40 oC using $30 \mathrm{~mL}$ of isopropyl alcohol mixed with $0.3 \mathrm{mmol}$ $\mathrm{KOH}, 3 \mathrm{mmol}$ nitrobenzene, and $100 \mathrm{mg}$ catalyst. ${ }^{b}$ Reaction time $5 \mathrm{~h}$. ${ }^{\mathrm{c}}$ Reaction time $3 \mathrm{~h} .{ }^{\mathrm{d}}$ Reaction time $6 \mathrm{~h}$. Reproduced with permission from Ref. ${ }^{110}$

The solvent used in reactions also plays a part in affecting the reactive behaviours of reactants. ${ }^{112,113,114} \mathrm{In}$ plasmonic photocatalysis, Xiao and co-workers' mentioned the effect of solvent for the oxidative esterification of 1-octanol using Au-Pd@HT- $\mathrm{PO}_{4}{ }^{3-}$ catalyst under visible light irradiation. ${ }^{68}$ The selectivity of ester products was remarkably affected through two approaches, first, the solvent may take part in reaction as another reactant (please see Table 5), when methanol, ethanol or other alcohols was used as solvent; second, if the solvent did not participate the reaction (please see Table 6), the physicochemical properties like its molecular polarity may affect the behaviours of reactants (e.g. adsorption and activation), thereby influencing the product selectivity. ${ }^{36}$

Table 5 Photocatalytic base-free selective oxidative cross couplings of aryl alcohols with alkyl alcohols ${ }^{\mathrm{a}}$

\begin{tabular}{|l|l|l|l|l|}
\hline Entry & Solvent & Reactant & Product & Yield (\%) \\
\hline $1^{\mathrm{c}}$ & Methanol & & $76(50)$ \\
\hline $2^{\mathrm{c}}$ & Methanol & & \\
\hline $3^{\mathrm{d}}$ & Ethanol & & \\
\hline $4^{\mathrm{e}}$ & $1-$ OH & & \\
\hline $5^{f}$ & n-heptane & & \\
\hline
\end{tabular}

Reaction conditions: Au-Pd@HT-PO ${ }_{4}^{3-}$ catalyst, $50 \mathrm{mg}$; reactant, $0.2 \mathrm{mmol} ; 2 \mathrm{~mL}$ of solvent; $1 \mathrm{~atm}$ of $\mathrm{O}_{2} ; 55^{\circ} \mathrm{C} ; 24 \mathrm{~h}$; light intensity, $0.5 \mathrm{~W} / \mathrm{cm}^{2}{ }^{\mathrm{b}}$. The yields were calculated from the product formed and the reactant converted, as measured by $\mathrm{GC}$; the values in parentheses are the results in the dark. Reproduced with permission from Ref. ${ }^{68}$

Table 6 The solvent effect for the oxidative esterification of 1octanol using Au-Pd@HT-PO${ }^{3-}$ catalyst under visible light Irradiation

\begin{tabular}{|l|l|l|l|l|}
\hline Entry & Solvent & $\begin{array}{l}\text { Conv. } \\
(\%)\end{array}$ & $\begin{array}{l}\text { Ester } \\
\text { sele. (\%) }\end{array}$ & $\begin{array}{l}\text { Yield } \\
(\%)\end{array}$ \\
\hline
\end{tabular}

\begin{tabular}{|l|l|l|l|l|}
\hline 1 & $\alpha, \alpha, \alpha$-trifluorotoluene & 94 & 76 & 72 \\
\hline 2 & n-heptane & 75 & 77 & 58 \\
\hline 3 & toluene & 51 & 49 & 25 \\
\hline 4 & acetonitrile & 25 & 4 & 1 \\
\hline 5 & isopropanol & 5 & 0 & 0 \\
\hline
\end{tabular}

Reaction conditions: Au-Pd@HT-PO ${ }_{4}^{3-}$ catalyst 100 mg, reactant $0.2 \mathrm{mmol}$, additive $50 \mathrm{mg}$, solvent $2 \mathrm{~mL}, 1 \mathrm{~atm} \mathrm{O}_{2}$, $55^{\circ} \mathrm{C}, 24 \mathrm{~h}$. Light intensity was $0.5 \mathrm{~W} / \mathrm{cm}^{2}$. Reproduced with permission from Ref. ${ }^{68}$

The additives affect the catalytic selectivity as shown in Table 7. ${ }^{68}$ To understand the effect of various bases on the performance of the catalytic system, Au$\mathrm{Pd} @ \mathrm{ZrO}_{2}$ catalysts with various base additives were investigated, revealing that when using $\mathrm{K}_{3} \mathrm{PO}_{4}$ as the base the photocatalytic reaction exhibited the best performance, and this is in agreement with the literature report that $\mathrm{K}_{3} \mathrm{PO}_{4}$ is the optimal base additive for the oxidative esterification. In another study, the authors investigated the effect of additives on the same reaction over $\mathrm{Au} / \mathrm{ZrO}_{2}$ catalysts and found that they dramatically influence the catalytic selectivity of esters (Table 8). ${ }^{115}$

Table 7 Base additive activity test using Au-Pd@ $\mathrm{ZrO}_{2}$ for oxidative esterification of 1-octanol.

\begin{tabular}{|l|l|l|l|}
\hline Entry & Additive & $\begin{array}{l}\text { Conv. } \\
(\%)\end{array}$ & $\begin{array}{l}\text { Sele. } \\
(\%)\end{array}$ \\
\hline 1 & -- & 38 & 47 \\
\hline 2 & $\mathrm{NaOH}$ & 80 & 97 \\
\hline 3 & $\mathrm{Na}_{2} \mathrm{CO}_{3}$ & 51 & 41 \\
\hline 4 & $\mathrm{~K}_{2} \mathrm{CO}_{3}$ & 78 & 55 \\
\hline 5 & $\mathrm{Cs}_{2} \mathrm{CO}_{3}$ & 62 & 40 \\
\hline 6 & $\mathrm{~K}_{3} \mathrm{PO}_{4}$ & 92 & 87 \\
\hline
\end{tabular}

Reaction conditions: catalyst $100 \mathrm{mg}$, reactant $0.2 \mathrm{mmol}$, additive $50 \mathrm{mg}$, solvent $2 \mathrm{~mL}, 1 \mathrm{~atm} \mathrm{O}_{2}, 55^{\circ} \mathrm{C}, 24 \mathrm{~h}$. Light intensity $0.5 \mathrm{~W} / \mathrm{cm}^{2}$. Reproduced with permission from Ref. ${ }^{68}$

Table 8 Activity test and catalyst screening of different $\mathrm{Au}$ content for oxidative esterification of 1-octanol.

\begin{tabular}{|l|l|l|l|l|l|}
\hline Entry & Additive & $\begin{array}{l}\text { Conv. } \\
(\%)\end{array}$ & $\begin{array}{l}\text { Sele. } \\
(\%)\end{array}$ & $\begin{array}{l}\text { Yield } \\
(\%)\end{array}$ & $\mathrm{TON}^{\mathrm{a}}$ \\
\hline 1 & $\mathrm{Au} / \mathrm{ZrO}_{2}(0.5 \mathrm{wt} \%)$ & 86 & 97 & 83 & 131 \\
\hline 2 & $\mathrm{Au} / \mathrm{ZrO}_{2}(1.5 \mathrm{wt} \%)$ & 96 & 99 & 95 & 50 \\
\hline 3 & $\mathrm{Au} / \mathrm{ZrO}_{2}(3.0 \mathrm{wt} \%)$ & 100 & 99 & 99 & 26 \\
\hline 4 & $\mathrm{Au} / \mathrm{ZrO}_{2}(5.0 \mathrm{wt} \%)$ & 91 & 99 & 90 & 14 \\
\hline 5 & $\mathrm{ZrO}_{2}$ & 0 & 0 & 0 & 0 \\
\hline
\end{tabular}

Reaction conditions: $\mathrm{Au} / \mathrm{ZrO}_{2}$ catalyst $50 \mathrm{mg}$, reactant 0.2 $\mathrm{mmol}, \mathrm{NaOH} 0.25 \mathrm{mmol}$, solvent $2 \mathrm{~mL}, 1 \mathrm{~atm} \mathrm{O}, 45^{\circ} \mathrm{C}, 24 \mathrm{~h}$. aTON was calculated as $n_{\text {product }} / n_{N P s}$, where $n_{\text {product }}$ and $n_{N P s}$ 
were the mole number of the product formed and the active metal, respectively. Reproduced with permission from Ref. ${ }^{115}$

Other factors such as $\mathbf{p H}$ values: The acidity/basicity of a solution affects the catalytic process in many reactions. In the plasmon-assisted photocatalysis, Sun and coworkers investigated the The $\mathrm{pH}$-controlled plasmonassisted surface photocatalysis reaction of 4aminothiophenol to DMAB on $\mathrm{Au}, \mathrm{Ag}$, and $\mathrm{Cu}$ colloids experimentally and theoretically, and they reported that plasmon-assisted surface photocatalysis reaction can be efficiently controlled by different $\mathrm{pH}$ values. When $\mathrm{pH}=$ 3 , the surface photocatalysis reaction cannot occur; however under neutral and alkaline conditions $(\mathrm{pH}=7$ and 10), such a reaction does take place. ${ }^{116}$ Cui and coworkers reported the selective plasmon-driven catalysis for para-nitroaniline in aqueous environments, and they found that Para-nitroaniline (PNA) with both nitro ($\left.\mathrm{NO}_{2}\right)$ and amine $\left(-\mathrm{NH}_{2}\right)$ groups is selectively catalysed to 4,4'-diamino-azobenzene (DAAB) through the plasmon-assisted dimerisation of the nitro $\left(-\mathrm{NO}_{2}\right)$ group into an azo group in an aqueous environment. ${ }^{117}$ This indicates that the plasmon-driven reduction of the nitro $\left(-\mathrm{NO}_{2}\right)$ group clearly occurs before the oxidation of the amine $\left(-\mathrm{NH}_{2}\right)$ group in an aqueous environment. However, in an ambient environment, the plasmondriven oxidation reaction via the amine group $\left(-\mathrm{NH}_{2}\right)$ is favored over the plasmon-driven reduction reaction via the nitro group. ${ }^{118,119}$ This phenomenon is explained by the abundant $\mathrm{O}_{2}$ on the substrate, which plays core role in the oxidation of the amine groups in ambient environments. ${ }^{\mathbf{1 2 0}}$ In contrast, amine oxidation is greatly restrained in an aqueous environment. The reduction of the nitro group is usually triggered by the hot electrons, which were generated from plasmon decay, ${ }^{121,}{ }^{122}$ which would not be greatly affected by the reaction environment. Therefore, the reduction process of the nitro group is favored over the oxidation process of the amine group in an aqueous environment.

\subsection{Summary of selectivity enhancement}

The following Table 9 summarises the mechanism of selectivity enhancement induced by the plasmonic effect, excluding like shape selectivity which is obtained by the design of catalyst structures. From the literature reports, eight major enhancement mechanisms can be summarised (to be clear, this category may be arbitrary but can reflect the general ones): (1) catalysts composition (e.g. change in elemental composition, oxidation state or content), (2) contribution of hot electrons transfer (e.g. broader or stronger band photoabsorption, photothermal effect, stronger active sitereactant interaction, electron-hole separation), (3) enhanced local electric fields on photocatalysts (e.g. near-field enhancement), (4) supports contribution (e.g. bifunctional catalysts and synergistic effect), (5) light sources (e.g. type, wavelength, intensity), and (6) reaction environment, (e.g. solvent, additives, $\mathrm{pH}$ conditions). All the comparisons are listed in the following Table 9.

Table 9 Lists some typical research and their approaches to selective enhancement (not activity)

\begin{tabular}{|c|c|c|c|}
\hline Photocatalysts & Reaction systems & Claimed enhancing/regulating mechanism & Ref \\
\hline $\begin{array}{l}2 \% \mathrm{Ag} / \mathrm{TiO}_{2} \\
\text { (atomic percentage) }\end{array}$ & Selective enhancement of different reactants & $\begin{array}{l}\text { (2) stronger adsorption of reactants with certain } \\
\text { functional groups, e.g. } \mathrm{C}=\mathrm{O} \text { and } \mathrm{C}-\mathrm{O}\end{array}$ & 102 \\
\hline $\mathrm{Au}, \mathrm{Cu}$ colloids & $\begin{array}{l}\text { 4-Aminothiophenol to } p, p^{\prime}- \\
\text { dimercaptoazobenzene }\end{array}$ & (6) controlling reaction environments: $\mathrm{pH}$ & \\
\hline Au colloids & $\begin{array}{l}\text { Oxidation of sec-Phenethyl and } \\
\text { Benzyl Alcohols to acetophenone and } \\
\text { benzaldehyde, respectively }\end{array}$ & (5) type of light source & \\
\hline $\begin{array}{l}\text { 3\%Au/Y zeolites } \\
\text { (weight percentage) }\end{array}$ & aromatic alcohols oxidation to aldehydes & $\begin{array}{l}\text { (2) stronger adsorption or electron interaction with } \\
\text { reactants }\end{array}$ & 23 \\
\hline $\begin{array}{l}\text { 1\%(wt) } \mathrm{Au}, \mathrm{Pt} \text { or } \\
\mathrm{Ag} / \mathrm{TiO}_{2}\end{array}$ & Oxidation of benzene to phenol & $\begin{array}{l}\text { (1) change in elemental composition or content, (2) } \\
\text { direct electron transfer }\end{array}$ & 1 \\
\hline $\begin{array}{l}\text { Ag substrate } \\
\text { (electrodes) }\end{array}$ & $\begin{array}{l}\text { Selective catalyse Para-nitroaniline (reduction } \\
\text { occurs before oxidation) }\end{array}$ & $\begin{array}{l}\text { (6) reaction environment, aqueous medium versus } \\
\text { ambient environment }\end{array}$ & 71 \\
\hline $\mathrm{Cu}$, and $\mathrm{Cu}_{2} \mathrm{O}$ & Propylene epoxidation & $\begin{array}{l}\text { (1) change in oxidation state, elemental } \\
\text { composition or content }\end{array}$ & 92 \\
\hline $\mathrm{Au}-\mathrm{Pd} @ \mathrm{HT}-\mathrm{PO}_{4}{ }^{3}$, & 1-octanol to giveoctyl octanoate (self- & (6) effect of additives, solvent, or supports & 68 \\
\hline
\end{tabular}




\begin{tabular}{|l|l|l|}
\hline $\mathrm{ZrO}_{2}, \mathrm{Al}_{2} \mathrm{O}_{3}, \mathrm{MgO}, \mathrm{HT}$ & esterification) & \\
\hline $\mathrm{Au} / \mathrm{ZrO} 2$ & Self-esterification of aliphatic alcohols & (6) reaction conditions: basic additives \\
\hline $\mathrm{Au}-\mathrm{Cu}$ alloy/ZrO 2 & Reduction of nitrobenzene to aniline & $\begin{array}{l}(1) \text { change in oxidation state, elemental } \\
\text { composition or content }\end{array}$ \\
\hline
\end{tabular}

\section{Outlook}

Governing the process and outcome of chemical reactions is one of the most important aims of catalytic chemistry, and thus the development of catalytic materials is critical to achieving these goals. Compared with conventional catalysis, photocatalysis offers promising future for energy conversion and chemical synthesis because it not only harvests sustainable solar energy, but also occurs at ambient temperature, which is pivotal to reduce side products. ${ }^{\mathbf{1 2 4}}$ To this end, the key is to create novel photocatalytic nanomaterials with controllable physiochemical properties, designer nanostructures, and high efficiency. This review summarises recent advances in plasmon-mediated nanomaterials, covering single or bimetallic/alloy nanostructures and non-metallic ones, and their contributions in selective enhancement and catalytic selectivity regulation. On the basis of these studies, we can predict some future prospects in this area.

(1) As to the nanomaterials development, a big challenge is to create new photocatalytic nanomaterials and then to design catalysts with controllable active sites and strong stability that allow them to sustain in water solvent, particularly under harsh conditions. Recent studies reveal that the MXenes derived from MAX phases are a potential family of photocatalytic materials or support. ${ }^{125},{ }^{126}$ Coupling with plasmonic nanostructures, desired catalytic performances can be expected. Moreover, considering the expense of noble metal-based nanomaterials, the development of alloystructured and non-metallic nanomaterials is promising. (2) As to the catalysts preparation technology or method, control of active sites with high accuracy is a potential approach, such as the single-atom catalysts, ${ }^{127,}$ 128, 129 catalysts prepared by Atomic Layer Deposition, ${ }^{\mathbf{1 3 0}}$ metal-semiconductor catalysts with controlled configurations and overgrowth of nanocrystals. ${ }^{131}$ To enlarge this part, the confinement of active sites inside nanosized spaces provides a powerful strategy to achieve this goal. Reacting molecules (reactants, intermediates, and products of a reaction) and nanomaterials (metal/metal-oxide nanoparticles) confined inside nanoreactors have been observed to exhibit modified behaviours and properties with respect to their unconfined counterparts. Typically, catalysts confined in zeolites, mesoporous materials, metal-organic frameworks, and nanotubes are obtained by traditional liquid-phase methods. However, excess metals or undesired solvents and other reagents must be removed. It is also difficult to precisely regulate the confined nanostructures and assemble multifunctional sites in the confined nanospaces. Atomic layer deposition (ALD) provides a controllable method to fabricate confined catalysts due to its outstanding advantages. (3) Designer nanostructures of catalysts and active sites distribution are important, particularly in cascade reactions in liquid phase. As for liquid-based catalysis, (hierarchical) macroporous or mesoporous catalysts are more advanced to minimise mass diffusion limitation than microporous materials, owing to the significant enhancements in inpore accessibility. ${ }^{\mathbf{1 3 2}}$ Besides the diffusion enhancement, hierarchical porous materials are also effective to stabilise high active site dispersion. Another potential way to design catalysts for cascade reaction is to construct bifunctional or multifunctional active sites in photocatalysts. A recent study reports a new concept of catalyst design by spatially orthogonal chemical functionalisation of the macroporous-mesoporous hierarchical pore network of silica supports with sizecontrolled Pd NPs in macropores and Pt NPs in mesopores for the catalytic cascade oxidation of cinnamyl alcohol to cinnamic acid via cinnamaldehyde. ${ }^{133}$ The spatial compartmentalisation of two metal active sites (Pd for producing cinnamaldehyde and Pt for producing cinamic acid) offers good selox performance. This new concept of catalyst design is extendable to diverse multifunctional catalyst development and is especially advantageous for cascade reactions in which the starting reactant undergoes a reaction and its product becomes the reactant for the next step, and so on, until a stable product is accumulated. ${ }^{\mathbf{1 3 4}}$ (5) The investigation into reaction mechanism and pathways is imperative to have detailed understanding of the change in catalysts and reactions. This will offer valuable information for researchers to create, design, or tailor photocatalysts from the intrinsic point of view. (6) Stability should be considered in developing new catalysts when it comes to real applications. For example, 
comparing the stability of $\mathrm{Au} / \mathrm{SiO}_{2}$ with $\mathrm{Au} / \mathrm{TiO}_{2}$ in the selective hydrogenation of Butadiene, Masoud and coworkers found that the $\mathrm{TiO}_{2}$-supported catalysts showed a steady loss of activity, which was recovered by heating in air. The deactivation was not caused by significant metal particle growth or SMSI, but rather, it is related to the deposition of carbonaceous species under reaction conditions. In contrast, all the $\mathrm{SiO}_{2}$-supported catalysts were highly stable, with very limited formation of carbonaceous deposits. It shows that $\mathrm{SiO}_{2}$-supported catalysts, despite their 2-3 times lower initial activities, clearly outperform $\mathrm{TiO}_{2}$-supported catalysts within a day of run time. ${ }^{135}$

The above-suggested strategies are just one corner of an iceberg. Additionally, the development in theoretical/ computational prediction or simulation would play a more and more important role in the future to assist the design of new catalytic materials or to assist the understanding of underlying catalytic mechanism on activity and selectivity. Overall, we anticipate that this review will provide fundamental inspiring information for researchers and scientists to develop new catalytic materials and to understand their catalytic mechanisms.

\section{Acknowledgements}

We thank the NSFC (????????) and NSFC Jiangsu (??????) for financial support.

\section{References}

1. A. Kubacka, M. Fernández-García and G. Colón, Chemical Reviews, 2012, 112, 1555-1614.

2. G. Palmisano, E. Garcia-Lopez, G. Marci, V. Loddo, S. Yurdakal, V. Augugliaro and L. Palmisano, Chemical Communications, 2010, 46, 7074-7089.

3. C. K. Prier, D. A. Rankic and D. W. C. MacMillan, Chemical Reviews, 2013, 113, 5322-5363.

4. C. Li, Y. Xu, W. Tu, G. Chen and R. Xu, Green Chemistry, 2017, 19, 882-899.

5. C. Chen, W. Ma and J. Zhao, Chemical Society Reviews, 2010, 39, 4206-4219.

6. R. Asahi, T. Morikawa, T. Ohwaki, K. Aoki and Y. Taga, Science, 2001, 293, 269-271.

7. Y. Qu and X. Duan, Chemical Society Reviews, 2013, 42, 2568-2580.

8. S. Linic, P. Christopher and D. B. Ingram, Nat Mater, 2011, 10, 911-921.

9. S. K. Cushing and N. Wu, The Journal of Physical Chemistry Letters, 2016, 7, 666-675.

10. C. An, S. Wang, Y. Sun, Q. Zhang, J. Zhang, C. Wang and J. Fang, Journal of Materials Chemistry A, 2016, 4, 4336-4352.
11. X. Meng, L. Liu, S. Ouyang, H. Xu, D. Wang, N. Zhao and J. Ye, Advanced Materials, 2016, 28, 6781-6803.

12. S. Sarina, E. R. Waclawik and H. Zhu, Green Chemistry, 2013, 15, 1814-1833.

13. H. Cheng, T. Kamegawa, K. Mori and H. Yamashita, Angewandte Chemie, 2014, 126, 2954-2958.

14. S.-W. Hsu, W. Bryks and A. R. Tao, Chemistry of Materials, 2012, 24, 3765-3771.

15. K. Manthiram and A. P. Alivisatos, Journal of the American Chemical Society, 2012, 134, 3995-3998.

16. D. Kumar, A. Lee, T. Lee, M. Lim and D.-K. Lim, Nano Letters, 2016, 16, 1760-1767.

17. J. Y. Park, L. R. Baker and G. A. Somorjai, Chemical Reviews, 2015, 115, 2781-2817.

18. L. Gomathi Devi and R. Kavitha, Applied Surface Science, 2016, 360, Part B, 601-622.

19. I. H. Karampelas, K. Liu, F. Alali and E. P. Furlani, The Journal of Physical Chemistry C, 2016, 120, 7256-7264.

20. Y. Jin, Advanced Materials, 2012, 24, 5153-5165.

21. H. Chen, L. Shao, Q. Li and J. Wang, Chemical Society Reviews, 2013, 42, 2679-2724.

22. R. H. Ritchie, Physical Review, 1957, 106, 874-881.

23. J. Henzie, J. Lee, M. H. Lee, W. Hasan and T. W. Odom, Annual Review of Physical Chemistry, 2009, 60, 147-165.

24. P. V. Kamat, The Journal of Physical Chemistry B, 2002, 106, 7729-7744.

25. W. L. Barnes, A. Dereux and T. W. Ebbesen, Nature, 2003, 424, 824.

26. X. Zhang, 2014.

27. H. Zhu, X. Chen, Z. Zheng, X. Ke, E. Jaatinen, J. Zhao, C. Guo, T. Xie and D. Wang, Chemical Communications, 2009, 7524-7526.

28. A. O. Govorov, H. Zhang, H. V. Demir and Y. K. Gun'ko, Nano Today, 2014, 9, 85-101.

29. G. Baffou and R. Quidant, Chemical Society Reviews, 2014, 43, 3898-3907.

30. M. S. Shore, J. Wang, A. C. Johnston-Peck, A. L. Oldenburg and J. B. Tracy, Small, 2011, 7, 230-234.

31. L. Tang, S. E. Kocabas, S. Latif, A. K. Okyay, D.-S. Ly-Gagnon, K. C. Saraswat and D. A. B. Miller, Nat Photon, 2008, 2, 226-229.

32. W. A. Challener, C. Peng, A. V. Itagi, KarnsD, W. Peng, Y. Peng, X. Yang, X. Zhu, N. J. Gokemeijer, Y. T. Hsia, JuG, R. E. Rottmayer, M. A. Seigler and E. C. Gage, Nat Photon, 2009, 3, 220-224.

33. Q. Gan, F. J. Bartoli and Z. H. Kafafi, Advanced Materials, 2013, 25, 2385-2396.

34. K. Awazu, M. Fujimaki, C. Rockstuhl, J. Tominaga, H. Murakami, Y. Ohki, N. Yoshida and T. Watanabe, Journal of the American Chemical Society, 2008, 130, 1676-1680.

35. X. Zhang, X. Ke, A. Du and H. Zhu, Scientific Reports, 2014, 4, 3805. 
36. X. Zhang, A. Du, H. Zhu, J. Jia, J. Wang and X. Ke, Chemical Communications, 2014, 50, 13893-13895.

37. D. Chen, X. Zhang and A. F. Lee, Journal of Materials Chemistry A, 2015, 3, 14487-14516.

38. M. R. Khan, T. W. Chuan, A. Yousuf, M. N. K. Chowdhury and C. K. Cheng, Catalysis Science \& Technology, 2015, 5, 2522-2531.

39. M. Wang, M. Ye, J. Iocozzia, C. Lin and Z. Lin, Advanced Science, 2016, 3, n/a-n/a.

40. Z. Zhang and J. T. Yates, Chemical Reviews, 2012, 112, 5520-5551.

41. M. L. Brongersma, N. J. Halas and P. Nordlander, Nat Nano, 2015, 10, 25-34.

42. E. Hutter and J. H. Fendler, Advanced Materials, 2004, 16, 1685-1706.

43. S. Link and M. A. El-Sayed, The Journal of Physical Chemistry B, 1999, 103, 4212-4217.

44. C. B. S. Link, Z.L. Wang, M.A. El-Sayed, J Chem Phys, 1999, 111 1255-1264.

45. H. Yuan, W. Ma, C. Chen, J. Zhao, J. Liu, H. Zhu and X. Gao, Chemistry of Materials, 2007, 19, 15921600.

46. T. Yan, X. Zhong, A. E. Rider, Y. Lu, S. A. Furman and K. Ostrikov, Chemical Communications, 2014, 50, 3144-3147.

47. J. L. Wang, R. A. Ando and P. H. C. Camargo, ACS Catalysis, 2014, 4, 3815-3819.

48. J. Qiu, N. E. Richey, J. S. DuChene, Y. Zhai, Y. Zhang, L. McElwee-White and W. D. Wei, The Journal of Physical Chemistry C, 2016, 120, 2077520780.

49. H. Liu, T. Liu, L. Zhang, L. Han, C. Gao and Y. Yin, Advanced Functional Materials, 2015, 25, 54355443.

50. X. Sun and D. Qin, Journal of Materials Chemistry C, 2015, 3, 11833-11841.

51. A. G. M. da Silva, T. S. Rodrigues, V. G. Correia, T. V. Alves, R. S. Alves, R. A. Ando, F. R. Ornellas, J. Wang, L. H. Andrade and P. H. C. Camargo, Angewandte Chemie International Edition, 2016, 55, 7111-7115.

52. S. W. Verbruggen, M. Keulemans, M. Filippousi, D. Flahaut, G. Van Tendeloo, S. Lacombe, J. A. Martens and S. Lenaerts, Applied Catalysis B: Environmental, 2014, 156-157, 116-121.

53. S. W. Verbruggen, M. Keulemans, B. Goris, N. Blommaerts, S. Bals, J. A. Martens and S. Lenaerts, Applied Catalysis B: Environmental, 2016, 188, 147-153.

54. Q. Zhang, J. Xie, J. Y. Lee, J. Zhang and C. Boothroyd, Small, 2008, 4, 1067-1071.

55. R. He, Y.-C. Wang, X. Wang, Z. Wang, G. Liu, W. Zhou, L. Wen, Q. Li, X. Wang, X. Chen, J. Zeng and J. G. Hou, Nat. Commun., 2014, 5, 4327.

56. Z. Liu, Y. Huang, Q. Xiao and H. Zhu, Green Chemistry, 2016, 18, 817-825.
57. S. Guo, J. Li, S. Dong and E. Wang, The Journal of Physical Chemistry C, 2010, 114, 15337-15342.

58. Y. Rong, A. Dandapat, Y. Huang, Y. Sasson, L. Zhang, L. Dai, J. Zhang, Z. Guo and T. Chen, RSC Advances, 2016, 6, 10713-10718.

59. Z. Zhang, Z. Wang, S.-W. Cao and C. Xue, The Journal of Physical Chemistry C, 2013, 117, 2593925947.

60. C. Chen, L. Kuai, Y. Chen, Q. Wang, E. Kan and B. Geng, RSC Advances, 2015, 5, 98254-98259.

61. S. Shuang, R. Lv, Z. Xie and Z. Zhang, Scientific Reports, 2016, 6, 26670.

62. A. Tanaka, K. Hashimoto and H. Kominami, Journal of the American Chemical Society, 2014, 136, 586-589.

63. P. N. Njoki, L. V. Solomon, W. Wu, R. Alam and M. M. Maye, Chemical Communications, 2011, 47, 10079-10081.

64. X. Huang, Y. Li, Y. Chen, H. Zhou, X. Duan and Y. Huang, Angewandte Chemie International Edition, 2013, 52, 6063-6067.

65. H. Liu, M. Li, T. D. Dao, Y. Liu, W. Zhou, L. Liu, X. Meng, T. Nagao and J. Ye, Nano Energy, 2016, 26, 398-404.

66. S. Sarina, H. Zhu, E. Jaatinen, Q. Xiao, H. Liu, J. Jia, C. Chen and J. Zhao, Journal of the American Chemical Society, 2013, 135, 5793-5801.

67. Q. Xiao, S. Sarina, A. Bo, J. Jia, H. Liu, D. P. Arnold, Y. Huang, H. Wu and H. Zhu, ACS Catalysis, 2014, 4, 1725-1734.

68. Q. Xiao, Z. Liu, A. Bo, S. Zavahir, S. Sarina, S. Bottle, J. D. Riches and H. Zhu, Journal of the American Chemical Society, 2015, 137, 1956-1966.

69. T. Jiang, C. Jia, L. Zhang, S. He, Y. Sang, H. Li, Y. Li, X. Xu and H. Liu, Nanoscale, 2015, 7, 209-217.

70. L. Liu, S. Ouyang and J. Ye, Angewandte Chemie International Edition, 2013, 52, 6689-6693.

71. D. Tsukamoto, Y. Shiraishi, Y. Sugano, S. Ichikawa, S. Tanaka and T. Hirai, Journal of the American Chemical Society, 2012, 134, 6309-6315.

72. B. Li, T. Gu, T. Ming, J. Wang, P. Wang, J. Wang and J. C. Yu, ACS Nano, 2014, 8, 8152-8162.

73. P. Verma, Y. Kuwahara, K. Mori and H. Yamashita, Journal of Materials Chemistry A, 2015, 3, 1888918897.

74. H. J. Huang and B.-H. Liu, Catalysis Communications, 2014, 43, 136-140.

75. H.-M. Chiu, T.-H. Yang, Y.-C. Hsueh, T.-P. Perng and J.-M. Wu, Applied Catalysis B: Environmental, 2015, 163, 156-166.

76. W. Guo, Q. Qin, L. Geng, D. Wang, Y. Guo and Y. Yang, Journal of Hazardous Materials, 2016, 308, 374-385.

77. A. M. Watson, X. Zhang, R. Alcaraz de la Osa, J. M. Sanz, F. González, F. Moreno, G. Finkelstein, J. Liu 
and H. O. Everitt, Nano Letters, 2015, 15, 10951100.

78. X. Huang, S. Tang, X. Mu, Y. Dai, G. Chen, Z. Zhou, F. Ruan, Z. Yang and N. Zheng, Nat Nano, 2011, 6, 28-32.

79. B. Wu, J. Lee, S. Mubeen, Y.-S. Jun, G. D. Stucky and M. Moskovits, Advanced Optical Materials, 2016, 4, 1041-1046.

80. R. Long, K. Mao, M. Gong, S. Zhou, J. Hu, M. Zhi, Y. You, S. Bai, J. Jiang, Q. Zhang, X. Wu and Y. Xiong, Angewandte Chemie International Edition, 2014, 53, 3205-3209.

81. Y. Zhu, Z. Xu, W. Jiang, W. Yin, S. Zhong, P. Gong, R. Qiao, Z. Li and S. Bai, RSC Advances, 2016, 6, 56800-56806.

82. X. Meng and Z. Zhang, Applied Surface Science, 2017, 392, 169-180.

83. K. Ji, H. Arandiyan, P. Liu, L. Zhang, J. Han, Y. Xue, J. Hou and H. Dai, Nano Energy, 2016, 27, 515-525.

84. H. Fang, M. Hegde, P. Yin and P. V. Radovanovic, Chemistry of Materials, 2017, 29, 4970-4979.

85. H. P. Yixin Zhao, Yongbing Lou, Xiaofeng Qiu, JunJie Zhu, Clemens Burda, Journal of the American Chemical Society, 2009, 4253-4261.

86. J. Kim, A. Agrawal, F. Krieg, A. Bergerud and D. J. Milliron, Nano Letters, 2016, 16, 3879-3884.

87. F. Dong, Q. Li, Y. Sun and W.-K. Ho, ACS Catalysis, 2014, 4, 4341-4350.

88. X. Li, Y. Sun, T. Xiong, G. Jiang, Y. Zhang, Z. Wu and F. Dong, Journal of Catalysis, 2017, 352, 102112.

89. Y. Sun, Z. Zhao, W. Zhang, C. Gao, Y. Zhang and F. Dong, Journal of Colloid and Interface Science, 2017, 485, 1-10.

90. J. Guozhi, W. Peng, Z. Yanbang and C. Kai, Scientific Reports, 2016, 6, 25884.

91. Z. Zheng, B. Huang, X. Qin, X. Zhang, Y. Dai and M.-H. Whangbo, Journal of Materials Chemistry, 2011, 21, 9079-9087.

92. A. Marimuthu, J. Zhang and S. Linic, Science, 2013, 339, 1590-1593.

93. Q. Xiao, S. Sarina, E. R. Waclawik, J. Jia, J. Chang, J. D. Riches, H. Wu, Z. Zheng and H. Zhu, ACS Catalysis, 2016, 6, 1744-1753.

94. M. Ahmadi, H. Mistry and B. Roldan Cuenya, The Journal of Physical Chemistry Letters, 2016, 7, 3519-3533.

95. J. Shi, Chemical Reviews, 2013, 113, 2139-2181.

96. S. Surnev, A. Fortunelli and F. P. Netzer, Chemical Reviews, 2013, 113, 4314-4372.

97. X. Ke, S. Sarina, J. Zhao, X. Zhang, J. Chang and H. Zhu, Chemical Communications, 2012, 48, 35093511.

98. X. Ke, X. Zhang, J. Zhao, S. Sarina, J. Barry and H. Zhu, Green Chemistry, 2013, 15, 236-244.
99. T. Kropp, J. Paier and J. Sauer, Journal of the American Chemical Society, 2014, 136, 1461614625.

100. K. Na, S. Alayoglu, R. Ye and G. A. Somorjai, Journal of the American Chemical Society, 2014, 136, 17207-17212.

101. O. Y. Gutiérrez, S. Singh, E. Schachtl, J. Kim, E. Kondratieva, J. Hein and J. A. Lercher, ACS Catalysis, 2014, 4, 1487-1499.

102. H. Tran, K. Chiang, J. Scott and R. Amal, Photochemical \& Photobiological Sciences, 2005, 4, 565-567.

103. Y. K. Lee, C. H. Jung, J. Park, H. Seo, G. A. Somorjai and J. Y. Park, Nano Letters, 2011, 11, 4251-4255.

104. C. Boerigter, U. Aslam and S. Linic, ACS Nano, 2016, 10, 6108-6115.

105. T. Tatsuma, H. Nishi and T. Ishida, Chemical Science, 2017, 8, 3325-3337.

106. S. Mukherjee, F. Libisch, N. Large, O. Neumann, L. V. Brown, J. Cheng, J. B. Lassiter, E. A. Carter, P. Nordlander and N. J. Halas, Nano Letters, 2013, 13, 240-247.

107. X. Zhang, L. J. Durndell, M. A. Isaacs, C. M. A. Parlett, A. F. Lee and K. Wilson, ACS Catalysis, 2016, 6, 7409-7417.

108. G. L. Hallett-Tapley, M. J. Silvero, M. González-Béjar, M. Grenier, J. C. Netto-Ferreira and J. C. Scaiano, The Journal of Physical Chemistry C, 2011, 115, 10784-10790.

109. D. Friedmann, A. Hakki, H. Kim, W. Choi and D. Bahnemann, Green Chemistry, 2016, 18, 53915411.

110. H. Zhu, X. Ke, X. Yang, S. Sarina and H. Liu, Angewandte Chemie International Edition, 2010, 49, 9657-9661.

111. J. Zhao, Z. Zheng, S. Bottle, A. Chou, S. Sarina and H. Zhu, Chemical Communications, 2013, 49, 2676-2678.

112. D. Prat, J. Hayler and A. Wells, Green Chemistry, 2014, 16, 4546-4551.

113. P. J. Dyson and P. G. Jessop, Catalysis Science \& Technology, 2016, 6, 3302-3316.

114. M. A. Mellmer, C. Sener, J. M. R. Gallo, J. S. Luterbacher, D. M. Alonso and J. A. Dumesic, Angewandte Chemie International Edition, 2014, 53, 11872-11875.

115. F. Wang, Q. Xiao, P. Han, S. Sarina and H. Zhu, Journal of Molecular Catalysis A: Chemical, 2016, 423, 61-69.

116. M. Sun, Y. Huang, L. Xia, X. Chen and H. Xu, The Journal of Physical Chemistry C, 2011, 115, 9629-9636.

117. L. Cui, P. Wang, Y. Li and M. Sun, Scientific Reports, 2016, 6, 20458. 
118. Y. Fang, Y. Li, H. Xu and M. Sun, Langmuir, 2010, 26, 7737-7746.

119. B. Dong, Y. Fang, X. Chen, H. Xu and M. Sun, Langmuir, 2011, 27, 10677-10682.

120. Y.-F. Huang, M. Zhang, L.-B. Zhao, J.-M. Feng, D.-Y. Wu, B. Ren and Z.-Q. Tian, Angewandte Chemie International Edition, 2014, 53, 2353-2357.

121. L. Kang, P. Xu, B. Zhang, H. Tsai, X. Han and H.-L. Wang, Chemical Communications, 2013, 49, 3389-3391.

122. W. Huang, Q. Jing, Y. Du, B. Zhang, X. Meng, M. Sun, K. S. Schanze, H. Gao and P. Xu, Journal of Materials Chemistry C, 2015, 3, 5285-5291.

123. X. Zhang, X. Ke and H. Zhu, Chemistry - A European Journal, 2012, 18, 8048-8056.

124. C. Clavero, Nature Photonics, 2014, 8, 95.

125. V. M. Hong Ng, H. Huang, K. Zhou, P. S. Lee, W. Que, J. Z. Xu and L. B. Kong, Journal of Materials Chemistry A, 2017, 5, 3039-3068.

126. Z. Guo, J. Zhou, L. Zhu and Z. Sun, Journal of Materials Chemistry A, 2016, 4, 11446-11452.

127. X. Li, W. Bi, L. Zhang, S. Tao, W. Chu, Q. Zhang, Y. Luo, C. Wu and Y. Xie, Advanced Materials, 2016, 28, 2427-2431.

128. X.-F. Yang, A. Wang, B. Qiao, J. Li, J. Liu and T. Zhang, Accounts of Chemical Research, 2013, 46, 1740-1748.

129. G. Gao, Y. Jiao, E. R. Waclawik and A. Du, Journal of the American Chemical Society, 2016, 138, 6292-6297.

130. Z. Gao and Y. Qin, Accounts of Chemical Research, 2017, 50, 2309-2316.

131. H. Huang, L. Zhang, Z. Lv, R. Long, C. Zhang, Y. Lin, K. Wei, C. Wang, L. Chen, Z.-Y. Li, Q. Zhang, Y. Luo and Y. Xiong, Journal of the American Chemical Society, 2016, 138, 6822-6828.

132. C. M. A. Parlett, K. Wilson and A. F. Lee, Chemical Society Reviews, 2013, 42, 3876-3893.

133. C. M. A. Parlett, M. A. Isaacs, S. K. Beaumont, L. M. Bingham, N. S. Hondow, K. Wilson and A. F. Lee, Nat Mater, 2016, 15, 178-182.

134. K. C. Nicolaou, D. J. Edmonds and P. G. Bulger, Angewandte Chemie International Edition, 2006, 45, 7134-7186.

135. N. Masoud, L. Delannoy, H. Schaink, A. van der Eerden, J. W. de Rijk, T. A. G. Silva, D. Banerjee, J. D. Meeldijk, K. P. de Jong, C. Louis and P. E. de Jongh, ACS Catalysis, 2017, 7, 5594-5603. 